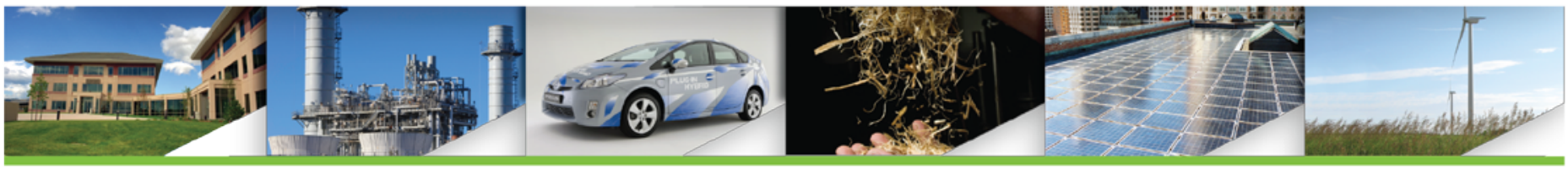

\title{
Estimating U.S. Methane Emissions from the Natural Gas Supply Chain: Approaches, Uncertainties, Current Estimates, and Future Studies
}

Garvin Heath ${ }^{1}$, Ethan Warner ${ }^{1}$, Daniel Steinberg ${ }^{1}$, and Adam Brandt ${ }^{2}$

${ }^{1}$ Joint Institute for Strategic Energy Analysis

${ }^{2}$ Stanford University

The Joint Institute for Strategic Energy Analysis is operated by the Alliance for Sustainable Energy, LLC, on behalf of the U.S. Department of Energy's National Renewable Energy Laboratory, the University of Colorado-Boulder, the Colorado School of Mines, the Colorado State University, the Massachusetts Institute of Technology, and Stanford University.

Technical Report

NREL/TP-6A50-62820

August 2015

Contract No. DE-AC36-08GO28308 


\title{
Estimating U.S. Methane
}

Emissions from the Natural

Gas Supply Chain:

\section{Approaches, Uncertainties,} Current Estimates, and Future Studies

\author{
Garvin Heath ${ }^{1}$, Ethan Warner ${ }^{1}$, Daniel \\ Steinberg ${ }^{1}$, and Adam Brandt ${ }^{2}$ \\ ${ }^{1}$ Joint Institute for Strategic Energy Analysis \\ ${ }^{2}$ Stanford University
}

Prepared under Task No. DOCC.LT19

The Joint Institute for Strategic Energy Analysis 15013 Denver West Parkway Golden, CO 80401 303-275-3000 • www.jisea.org
The Joint Institute for Strategic Energy Analysis is operated by the Alliance for Sustainable Energy, LLC, on behalf of the U.S. Department of Energy's National Renewable Energy Laboratory, the University of Colorado-Boulder, the Colorado School of Mines, the Colorado State University, the Massachusetts Institute of Technology, and Stanford University.

JISEA $^{\circledR}$ and all JISEA-based marks are trademarks or registered trademarks of the Alliance for Sustainable Energy, LLC.

Technical Report

NREL/TP-6A50-62820

August 2015

Contract No. DE-AC36-08GO28308 


\section{NOTICE}

This report was prepared as an account of work sponsored by an agency of the United States government. Neither the United States government nor any agency thereof, nor any of their employees, makes any warranty, express or implied, or assumes any legal liability or responsibility for the accuracy, completeness, or usefulness of any information, apparatus, product, or process disclosed, or represents that its use would not infringe privately owned rights. Reference herein to any specific commercial product, process, or service by trade name, trademark, manufacturer, or otherwise does not necessarily constitute or imply its endorsement, recommendation, or favoring by the United States government or any agency thereof. The views and opinions of authors expressed herein do not necessarily state or reflect those of the United States government or any agency thereof.

Available electronically at SciTech Connect: http:/www.osti.gov/scitech

Available for a processing fee to U.S. Department of Energy and its contractors, in paper, from:

U.S. Department of Energy Office of Scientific and Technical Information P.O. Box 62

Oak Ridge, TN 37831-0062

OSTI http://www.osti.gov

Phone: 865.576.8401

Fax: 865.576.5728

Email: reports@osti.gov

Available for sale to the public, in paper, from:

U.S. Department of Commerce National Technical Information Service 5301 Shawnee Road Alexandria, VA 22312

NTIS http://www.ntis.gov

Phone: 800.553 .6847 or 703.605 .6000

Fax: 703.605 .6900

Email: orders@ntis.gov 


\section{Foreword}

JISEA advances its mission of guiding the transformation of the global energy economy through conducting seminal analysis and innovative, collaborative research. JISEA papers and publications deliver groundbreaking strategic insights and explain their real-world implications.

We look forward to your feedback and thank you for your interest in the work of JISEA.

Doug Arent

Executive Director, Joint Institute for Strategic Energy Analysis 


\section{Acknowledgments}

This work was funded by the U.S. Department of Energy's (DOE's) Office of Energy Policy and Systems Analysis (EPSA). The authors wish to thank the following individuals for their thoughtful comments, input, and review of the document in its various stages: Elke Hodson, Adrian Down, and Judi Greenwald (DOE); Jeffrey Logan, Emily Newes, and Dave Mooney of the National Renewable Energy Laboratory (NREL); Doug Arent of the Joint Institute for Strategic Energy Analysis; David McCabe of the Clean Air Task Force (CATF); Fiji George of the Southwestern Energy Company; and Timothy Skone of the National Energy Technology Laboratory. These reviews serve to make this report as technically sound as possible, however, any remaining errors or omissions are those of the authors. Furthermore, the views and opinions of authors expressed herein do not necessarily state or reflect those of the reviewers, their associated institutions, or the United States government or of any institution thereof. We also wish to thank Scott Gossett and Kendra Palmer of NREL for their editorial support. 


\section{Acronyms and Abbreviations}

\begin{tabular}{ll}
$\mathrm{CBM}$ & coal bed methane \\
$\mathrm{CH}_{4}$ & methane \\
$\mathrm{CO}_{2}$ & carbon dioxide \\
$\mathrm{CO}_{2} \mathrm{e}$ & $\mathrm{CO}_{2}$ equivalent \\
$\mathrm{DOE}$ & U.S. Department of Energy \\
EIA & Energy Information Administration \\
EPA & Environmental Protection Agency \\
FY & funding year \\
GHG & greenhouse gas \\
GHGI & greenhouse gas inventory \\
GHGRP & greenhouse gas reporting program \\
GWP & global warming potential \\
$\mathrm{HAP}$ & hazardous air pollutants \\
IPCC & Intergovernmental Panel on Climate Change \\
LNG & liquefied natural gas \\
Mcf & thousand cubic feet \\
MMt & million metric tonnes \\
NG & natural gas \\
PM & particulate matter \\
t & metric tonnes \\
UNFCCC & United Nations Framework Convention on Climate \\
VOC & Change \\
yr & volatile organic compounds \\
\hline
\end{tabular}

iii 


\section{Glossary}

Activity Factor: Count of activities for an emission source category.

Anthropogenic: Originating in human activity.

Associated Gas: Natural gas extracted from deposits of petroleum. The natural gas is either dissolved in the oil or as a free "gas cap" above the oil in the deposit.

"Behind the Customer Meter": Natural gas infrastructure (i.e., pipes, fittings, valves and other components) after distribution service lines and customer meters, but before use (e.g., combustion) of the natural gas.

Bottom-up Study: these studies take a disaggregated approach to developing estimates of emissions at the level of individual sources and source categories.

- Inventory: Estimates emissions from sources and source categories based on the product of activity and emission factors then summed across all sources and source categories within the defined temporal, spatial and sectoral scope.

- Measurement: Measurements made directly from individual components, activities, or facilities. Multiple of such measurements often are used to develop emission factors used in inventories to estimate emissions from a given source or source category.

Coal Bed Methane (CBM) Gas: Natural gas produced from coal formations.

Conventional Gas: Natural gas produced from porous rock formations such as carbonates, sandstones, and siltstones that do not require stimulation to release the gas.

Emission Factor: An average mass of pollutant emitted per unit of activity from a population of emissions activities that represents an emission source category.

\section{Emission Source(s):}

- Source: Emissions from a single component, activity, or facility.

- Source Category: Emissions from a population of sources. The population is based on grouping similar sources. For example, natural gas production wells or gathering system pneumatic devices. Source categories used in this report match those used in the U.S. GHGI (EPA 2014a).

- Source Sector: A population of emission sources from an industrial sector (e.g., natural gas industry), which is the collection of all source categories in the selected source sector. Source sectors used in this report match those in the U.S. Greenhouse Gas Inventory (GHGI) (EPA 2014a).

Fugitives: Unintentional emissions to the atmosphere. 
GHGRP: Greenhouse Gas Reporting Program. In 2009, the U.S. EPA published a rule requiring reporting of $\mathrm{GHG}$ emissions from sources emitting $>25,000$ metric tonnes $(\mathrm{t})$ carbon dioxide equivalent $\left(\mathrm{CO}_{2} \mathrm{e}\right)$ per year, including many types of facilities in the natural gas industrial sector (EPA 2014d).

Service Lines: Pipelines in the distribution segment that transport gas from a common source of supply to an end user's meter or piping.

Shale Gas: Natural gas produced from shale formations, which requires hydraulic fracturing.

Tight Gas: Natural gas produced from low permeability reservoir rocks, which requires hydraulic fracturing.

Top-down Measurement Study: Top-down studies start with a measurement ("in-situ", or within the air mass) or estimate (e.g., from satellite remote sensing) of the concentration of methane in the atmosphere, and then use different modeling approaches to estimate mass flux (mass of methane emitted per unit time and area) from observed or estimated concentrations.

Unconventional gas: Any sources of natural gas that do not meet the definition of "conventional" gas. This includes CBM, shale gas, and tight gas.

Venting: Emissions emitted to the atmosphere by the design of routine operations, engine combustion, or other non-fugitive sources. 


\section{Executive Summary}

The annual Inventory of United States (U.S.) Greenhouse Gas Emissions and Sinks (GHGI) identifies and quantifies emission sources and sinks of greenhouse gases (GHG) from human activities in the United States as required by the United Nations Framework Convention on Climate Change (UNFCCC). The U.S. GHGI is a critical resource for understanding the U.S. contribution to global climate change, tracking trends in GHG emission sources and sinks, identifying and prioritizing abatement opportunities within the United States, and for informing policy and industrial decision making. Because they provide a high level of granularity and repeatability, inventories like the U.S. GHGI are relied upon by many governmental agencies (e.g., Federal Register 2014; White House 2015; DOE 2015), stakeholder organizations (e.g., Bradbury et al. 2013; Harvey, Gowrishankar, and Singer 2012; ICF 2014), researchers (e.g., Allen et al. 2015a; Heath et al. 2014a; Mitchell et al. 2015) and companies (e.g., Laurenzi and Jersey 2013) for analyses and decision making.

The energy sector was responsible for approximately $84 \%$ of carbon dioxide equivalent $\left(\mathrm{CO}_{2} \mathrm{e}\right)$ GHG emissions in the U.S. in 2012 (EPA 2014a). ${ }^{1}$ Methane is the second most important GHG, contributing $9 \%$ of total U.S. $\mathrm{CO}_{2}$ e GHG emissions. A large portion of those methane emissions result from fossil energy production and use; the natural gas, coal, and oil industries produce approximately $39 \%$ of anthropogenic methane emissions in the U.S. Over the last decade, the U.S. has experienced dramatic growth in the domestic natural gas and oil industries. As a result, estimates of GHG emissions from these industries in the U.S. GHGI as well as in other inventories have garnered heightened interest.

The U.S. GHGI is a unique resource to inform industrial and policy decision-making. It is based on the best available knowledge and methods, within constraints of UNFCCC requirements, and is continuously improved. Many recent studies (e.g., Brandt et al. 2014; Pieschl et al. 2015; Lamb et al. 2015; Zimmerle et al. 2015) have reported conflicting conclusions as to the magnitude of methane emissions from the natural gas and oil industries and how measured emissions compare to those estimated in the U.S. GHGI. Based on a review of recent research and analysis of the U.S. GHGI emission estimates, this report briefly summarizes the methods and results of the 2014 U.S. GHGI (EPA 2014a), discusses challenges to constructing the U.S. GHGI, and suggests some opportunities that could improve the accuracy of the methane emissions estimates.

This report builds on the solid foundation of past and current U.S. GHGIs to suggest opportunities to strengthen its accuracy and reduce uncertainty. Although this report focuses on the U.S. GHGI, to the extent other inventories share common methods, data sources, and challenges, the observations and conclusions discussed in this report could apply.

\section{Conclusions from Analysis of U.S. GHGI Results}

The U.S. GHGI classifies four main segments of the natural gas industry: (1) production, gathering and boosting ( $33 \%$ of total natural gas $[\mathrm{NG}]$ sector methane emissions in 2012$)$; (2) processing $(\sim 14 \%)$; (3) transmission and storage ( $\sim 33 \%)$; and (4) distribution $(\sim 20 \%)$ (EPA

\footnotetext{
${ }^{1}$ The U.S. GHGI reports emissions with a two year lag (e.g., the 2014 U.S. GHGI reports emissions through 2012). Until recently, the latest available U.S. GHGI was published in 2014 (EPA, 2014a). The 2014 U.S. GHGI was analyzed for this report; use of the 2015 U.S. GHGI would not change the conclusions of this report.
} 
2014a). Our analysis of the U.S. GHGI reveals that approximately $43 \%$ of total methane emissions across all four segments of the natural gas industry are from compressors and compressor stations, mostly from the processing and transmission and storage segments. We also find that leaks from cast iron and unprotected steel pipeline main and service lines contribute $33 \%$ of total distribution segment emissions despite representing the fewest miles of any piping material.

\section{Conclusions from Assessment of Challenges to Inventory Development}

A synthesis of more than 20 years of previous comparisons of methane emission estimates revealed a consistent gap between estimates originating from inventories as compared to those originating from direct measurements. Brandt et al. (2014) observed that across years, locations and scales, measurements of emissions were typically higher than those estimated by inventories including the U.S. GHGI, and highlighted the need for improvements to both approaches to reconcile the differences and better support decision making. This report builds on the discussion of the Brandt et al. (2014) study regarding challenges to inventory accuracy. In addition, we identify potential improvements to inventory methods, focusing on the U.S. GHGI. Finally, we discuss how integration of the results of recent and forthcoming studies since the Brandt et al. (2014) publication, including measurements from both "top-down"" atmospheric and "bottomup" 3 component-level perspectives ${ }^{4}$ could be used to improve the accuracy of inventory estimates, particularly the U.S. GHGI, and reduce uncertainties.

In their current states, neither measurement- (top-down or bottom-up) nor inventory-based estimates of methane emissions are considered "gold standard" benchmarks, yet both can be useful. For instance, top-down measurement studies can be compared to inventory emission estimates for validation purposes. Such comparisons are most useful when the system boundaries of both studies are well-aligned (spatially, temporally, and sectorally). Differences found in such comparisons can help form hypotheses potentially explaining any gaps between the estimates and suggest pathways for improvements for both approaches. Likewise, bottom-up measurement studies can update and augment emission factors used in inventories. Such studies would be most directly applicable and easily incorporated into inventories like the U.S. GHGI if they were designed for strong alignment with current inventory structure. Strong sampling design and

\footnotetext{
${ }^{2}$ Top-down studies start with a measurement ("in-situ", or within the air mass) or estimate (e.g., from satellite remote sensing) of the concentration of methane in the atmosphere, and then use different modeling approaches to estimate mass flux (mass of methane emitted per unit time and area) from the observed or estimated concentrations. ${ }^{3}$ Bottom-up studies can be based on modeling or measurement. Bottom-up modeling studies use engineering-based calculations (typically, as in the U.S. GHGI, estimated as an emission factor multiplied by an activity factor, or count of emission sources) to estimate emissions from each category of source (i.e., type of component or activity) emitting the pollutant of concern within a given area and time. The sum of emissions from each tracked source category is the inventory estimate, for instance, annual methane emissions from the domestic natural gas industry. Sometimes this process is performed at the facility instead of component or activity level. Bottom-up measurement studies are those that measure emissions directly at a given component, activity, or facility, and can be used to develop the emission factors that are used in inventories. Life cycle assessments are another form of bottom-up modeling study but are not discussed in this report.

${ }^{4}$ As this report is focused on potential improvements to the U.S. GHGI, and to some extent emissions inventories broadly, readers should seek more extensive description and discussion of bottom-up and top-down measurement study methods and their associated strengths and weaknesses elsewhere (e.g., Brandt et al. 2014). We only include discussion of these issues to the extent relevant to explaining how top-down and bottom-up measurement studies can contribute to bottom-up inventory improvements.
} 
robust sample size are also critical to maximize inventory improvement from new studies. Activity factor ${ }^{5}$ data sources and methods should advance in a complimentary fashion with emission factors.

Challenges exist for both top-down measurements and bottom-up inventories of methane emissions the natural gas industry. Those related to the accuracy of inventories include:

1. Completeness and accuracy of inventoried sources

2. Variable and heavily skewed distributions of emissions within a source category

3. Representativeness of emission samples

4. Quantifying uncertainty.

Each of these issues is described further in Section 4 of the report.

Based on examination of available evidence and of current challenges to both bottom-up and topdown studies as well as considering assumptions and limitations of inventories first described in Brandt et al. (2014), we identify a set of opportunities for improvement to estimates of methane emissions from inventories with particular attention to opportunities relevant to the U.S. GHGI given its prominent role. Section 5 describes these recommendations.

In conclusion, to maintain the critical functions of the U.S. GHGI and to address challenges to its accuracy in a rapidly-changing industrial sector such as natural gas, it is important to continually improve data sources and methods. This report offers analysis and guidance for agencies, researchers, and research-sponsoring organizations to consider when developing and designing studies that can help to improve accuracy of the U.S. GHGI and other inventories.

\footnotetext{
${ }^{5}$ Activity factor is a count of activities for an emission source category.
} 


\section{Table of Contents}

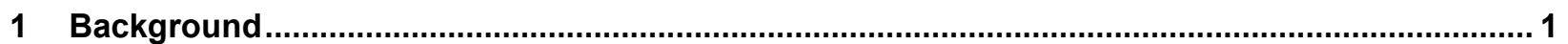

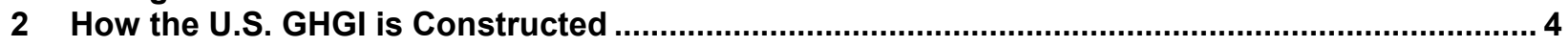

3 U.S. Methane Emissions from the Natural Gas Supply Chain ...................................................... 8

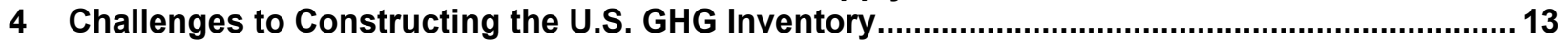

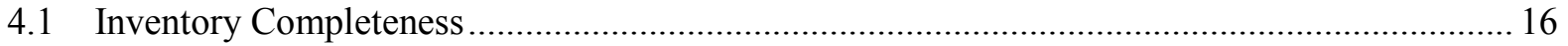

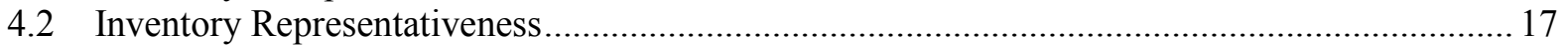

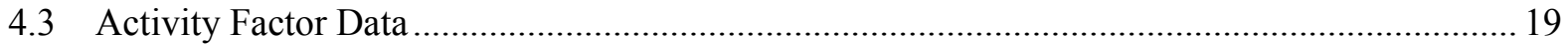

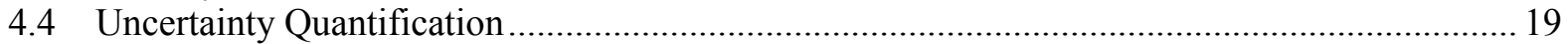

5 Recommendations for Improvements to the U.S. GHGI Leveraging Bottom-up and Top-down

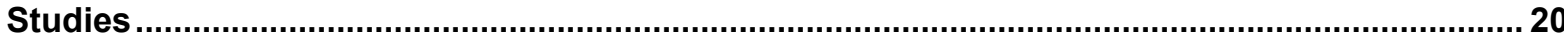

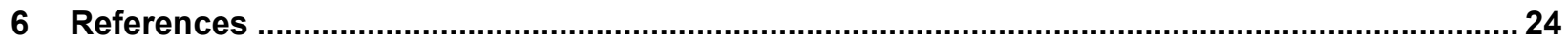

7 Measurement and Inventory Study References (as Displayed in Figures 6 and C-1) ............... 29

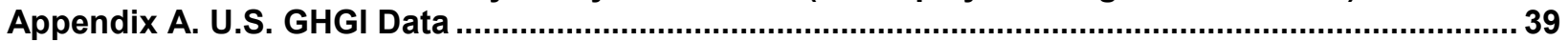

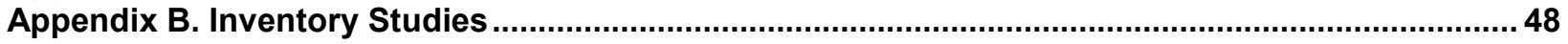

\section{List of Tables}

Table 1. U.S. Natural Gas Methane $\left(\mathrm{CH}_{4}\right)$ Activity Factor and Emission Factors in 2012 for Distribution Pipelines (Main Lines and Service Lines) as Reported in the U.S. GHGI............................. 12

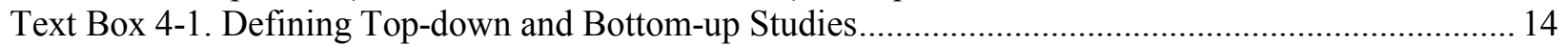

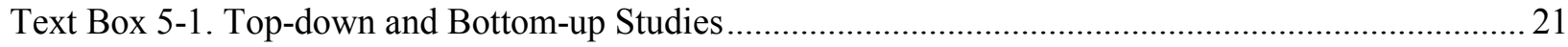

Table A-1. U.S. GHGI Estimates of Natural Gas Methane $\left(\mathrm{CH}_{4}\right)$ Emissions in 2012 from the Production and Gathering and Boosting Segment of the Natural Gas Supply Chain............................... 40

Table A-2. U.S. GHGI Estimates of Natural Gas Methane $\left(\mathrm{CH}_{4}\right)$ Emissions in 2012 from the Processing

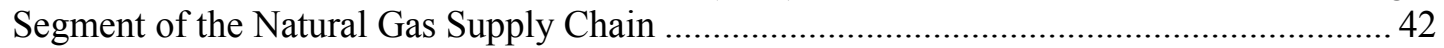

Table A-3. U.S. GHGI Estimates of Natural Gas Methane $\left(\mathrm{CH}_{4}\right)$ Emissions in 2012 from the Transmission and Storage Segment of the Natural Gas Supply Chain ................................... 44

Table A-4. U.S. GHGI estimates of natural gas methane $\left(\mathrm{CH}_{4}\right)$ emissions in 2012 from the distribution

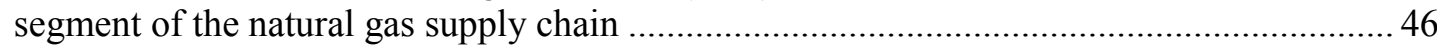

\section{List of Figures}

Figure 1. U.S. GHGI estimates of anthropogenic methane emissions in the U.S. in 2012 ....................... 3

Figure 2. Organization of the natural gas supply chain into four segments ........................................... 9

Figure 3. U.S. GHGI estimates of methane emissions from natural gas compressors within each supply

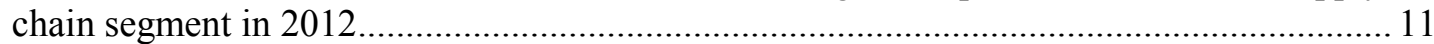

Figure 4. U.S. GHGI estimates of methane emissions from the U.S. natural gas distribution system (in

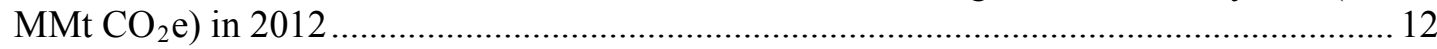

Figure 5. A recent synthesis of methane emission measurements that were compared to inventory estimates of methane emissions

Figure 6. Mapping of exemplary methane emission measurement studies published through February 2015 by type and location

Figure A-1. U.S. GHGI estimates of natural gas methane emissions in 2012 from the production and gathering and boosting segment of the natural gas supply chain

Figure A-2. U.S. GHGI estimates of natural gas methane emissions in 2012 from the processing segment

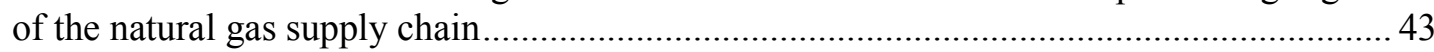

Figure A-3. U.S. GHGI estimates of natural gas methane emissions in 2012 from the transmission and

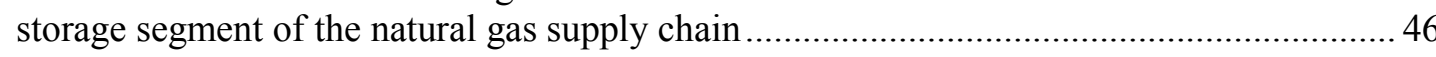

Figure B-1. Emission inventory studies through May 2014, aggregated by the type of emissions included and by location 


\section{Background}

Under the United Nations Framework Convention on Climate Change (UNFCCC), the United States (U.S.) is obligated to annually develop nationally representative estimates of emission sources and sinks of specific greenhouse gases (GHGs) ${ }^{6}$ from human activities ${ }^{7}$ for a time series starting with 1990. The U.S. fulfills the UNFCCC national GHG tracking and reporting responsibilities with its annual Inventory of the Greenhouse Gas Emissions and Sinks (GHGI) (EPA 2014a). The U.S. GHGI is a critical resource for understanding the U.S. contribution to global climate change, tracking trends in GHG emission sources and sinks, identifying and prioritizing emission sources, and informing policy and industrial decision making, including potential abatement opportunities.

An inventory represents an accounting of the sources of gases emitted or removed from the atmosphere over a period of time from a specific set of components, activities, or facilities and within a defined geographic area. The U.S. GHGI uses an engineering-based approach, described further in Section 2, to generate national GHG emission estimates for each source category tracked by the inventory based on the best available information. ${ }^{8}$ Each source category represents a grouping of similar components or activities. Tracking of emissions is done at relatively high resolution, e.g., there are almost 110 source categories tracked within the natural gas sector in the U.S. GHGI. The level of disaggregation of the U.S. GHGI enables analysis of the relative importance of GHG source categories over time. The U.S. GHGI can also be used to suggest priorities for GHG emission reductions (e.g., Bradbury et al. 2013; Harvey, Gowrishankar, and Singer 2012; ICF 2014).

The energy sector represented $84 \%$ of total U.S. GHG emissions in 2012 in the U.S. GHGI, with a similar percentage contribution in prior years (EPA 2014a). The dramatic growth of the domestic natural gas and oil industries over the last decade has heightened interest in the estimates of GHG emissions from these industries in the U.S. GHGI. Methane is the main component of natural gas, which is also a constituent of associated gas from oil production, and can be released from natural gas and oil production activities.

\footnotetext{
${ }^{6} \mathrm{CO}_{2}$, methane, nitrous oxide, hydrofluorocarbons, perfluorocarbons, and sulfur hexafluoride emission estimates have been historically required under the UNFCCC. Starting in 2015, countries are also required to report nitrogen trifluoride to the UNFCCC and may elect to report fluorinated ethers (UNFCCC 2014).

${ }^{7}$ UNFCCC requires use of IPCC guidance for calculation of national GHG inventories like the U.S. GHGI, which defines specific anthropogenic emissions and removals to be reported that are a result of human activities. There are other sources of methane emissions to the atmosphere that are natural (e.g., termites and natural wetlands) and therefore not included in the U.S. GHGI. As such, the U.S. GHGI does not by itself allow prioritization between all sources of GHG emissions for climate change mitigation, if natural sources are also considered.

${ }^{8}$ There are also cases of known emission sources having no available estimate of emissions, but these are likely relatively small emission contributors.
} 
Methane is an important climate forcing gas. Methane has a large global warming potential (GWP) relative to $\mathrm{CO}_{2}$, but shorter atmospheric lifetime (IPCC 2013). ${ }^{9}$ Thus, reducing methane emissions has been included in the interagency Methane Strategy of the President's Climate Action Plan White House 2015). It is therefore important to understand the sources and trends of methane emissions.

At the time of this analysis, the most current U.S. GHGI was published in 2014 (EPA 2014a). That U.S. GHGI used a methane GWP of 21, in conformance with UNFCCC reporting requirements for national GHG inventories (UNFCCC 1998), based on scientific consensus at the time (IPCC 1995). Starting in 2015, the UNFCCC reporting requires the use of a methane GWP of 25 (UNFCCC 2014; IPCC 2007). This report uses a GWP of 25 following its use in EPA's GHG Reporting Program as well as its recently published 2015 U.S. GHGI (EPA 2015a; EPA 2014b; Federal Register 2014). It should be noted, however, that recent scientific evidence suggests that the 100-year GWP of methane is greater than 25 (IPCC 2013). ${ }^{10}$

Nine percent of 2012 U.S. anthropogenic $\mathrm{CO}_{2}$-equivalent $\mathrm{GHG}$ emissions are from methane (EPA 2014a), making it the second most important GHG after $\mathrm{CO}_{2}$. The natural gas industry is consistently one of the largest contributors to U.S. methane emissions (e.g., $\sim 23 \%$, or 675 million metric tonnes [MMt] of $\mathrm{CO}_{2} \mathrm{e}$ in 2012) (EPA 2014a). In addition, another $6 \%$ of methane is emitted by the petroleum industry, in part through processes designed to separate and transport natural gas produced in association with oil.

\footnotetext{
${ }^{9}$ Global warming potential (GWP) is a metric defined as the time-integrated radiative forcing of a gas due to a pulse emission and relative to that of carbon dioxide, which by definition has a GWP of 1 . The GWP has become the default metric for transforming emissions of different gases to a common scale; often called "carbon dioxide equivalent $\left(\mathrm{CO}_{2} \mathrm{e}\right)$ emissions". GWP's are assessed over fixed time periods (e.g., 20, 100, and 500-years) since gases have different atmosphere lifetimes, with the 100 -year time horizon being the most commonly used. However these specific time horizons should not be considered as having any special scientific significance (IPCC 2013). The 100year GWP was later adopted as a metric to implement the multi-gas accounting approach embedded in the United Nations Framework Convention on Climate Change (IPCC 2013).

${ }^{10}$ The latest international assessment of scientific evidence (IPCC 2013) reports that the 100-year GWP for methane of fossil origin is $36 \mathrm{~g} \mathrm{CO}_{2}$ e per $\mathrm{g}$ methane when including climate-carbon feedbacks (IPCC 2013). If this GWP were used, all instances of GHG emissions in $\mathrm{CO}_{2} \mathrm{e}$ in this report would increase by about $45 \%$.
} 


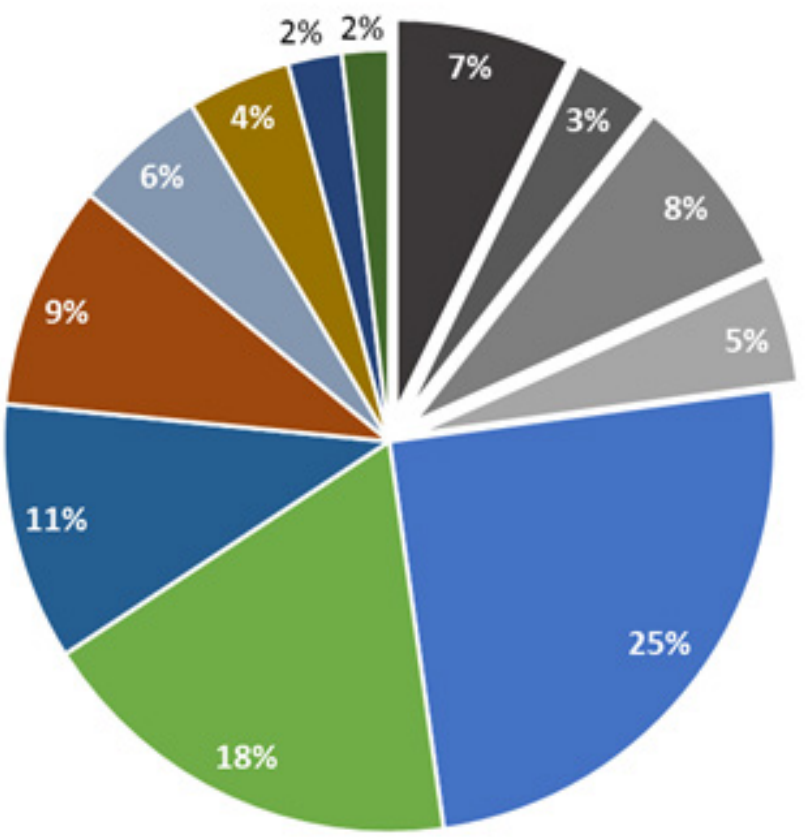

- NG Production
= NG Processing
= NG Transmission and Storage
= NG Distribution
= Enteric Fermentation
= Landfills
- Coal Mining (active and abandoned)
- Manure Management
= Petroleum Systems
- Other Agriculture
- Wastewater Treatment
- Other

Figure 1. U.S. GHGI estimates of anthropogenic methane emissions in the U.S. in 2012. Total emissions are $675 \mathrm{MMt} \mathrm{CO}_{2} \mathrm{e} / \mathrm{yr}$. (NG=natural gas)

Source: EPA 2014a

Recent studies (e.g., Brandt et al. 2014; Pieschl et al. 2015; Lamb et al. 2015; Zimmerle et al. 2015) have reported conflicting conclusions as to the magnitude of methane emissions from the natural gas and oil industries and how measured emissions compare to those reported in the U.S. GHGI and other inventories. Conflicting conclusions from measurement studies and inventories is an issue previously encountered with emission inventories for criteria air pollutants (Miller et al. 2006). Based on a review of recent research and analysis of the U.S. GHGI emission estimates, this report briefly summarizes the methods and results of the 2014 U.S. GHGI (EPA 2014a), discusses challenges to constructing a GHG inventory with particular focus on the U.S. GHGI, and suggests some opportunities that could improve the accuracy of the methane emissions estimates. Many of our recommendations are specific to the natural gas industrial sector, while others are more broadly applicable to improving inventory accuracy generally. Although this report focuses on the U.S. GHGI, to the extent other inventories share common methods, data sources, and challenges, the observations and conclusions discussed in this report could apply. 


\section{How the U.S. GHGI is Constructed}

The U.S. GHGI is constructed annually by the U.S. EPA and estimates emissions of the six GHGs required to be reported to UNFCCC $-\mathrm{CO}_{2}$, methane, nitrous oxide, hydro-fluorocarbons, perfluorocarbons, and sulfur hexafluoride ${ }^{11}$ _ from anthropogenic sources and sinks associated with energy, industrial processes, waste, agriculture, and land use (EPA 2014a). Natural gasrelated GHG emissions are primarily tracked in two different sections of the U.S. GHGI. Emissions from the natural gas industrial sector, the focus of this report, are tracked under the heading "Natural Gas Systems." Emissions from combustion of natural gas in residential, commercial, and industrial energy use are tracked under the heading "Fossil Fuel Combustion."

Production of natural gas can be classified as derived from onshore or offshore sources, with onshore consisting of conventional gas, tight gas, coal bed methane (CBM) gas, shale gas, and associated gas. Associated gas refers to natural gas produced from wells classified as oil wells. Currently, methane emissions from oil wells are for the most part tracked in the U.S. GHGI in the under the heading "Petroleum Systems" (including emissions from wells that produce coproducts like natural gas); ${ }^{12}$ once any oil-well co-produced natural gas enters natural gas infrastructure (i.e., as it is collected by gathering lines), the U.S. GHGI categorizes those GHG emissions in the natural gas sector. The focus of this report is on emissions from the natural gas sector, but where relevant, the oil sector will be mentioned with regards to the current U.S. GHGI and EPA's (2015a) proposed updates to allocation of associated well GHG emissions between the natural gas and petroleum sectors.

Within the natural gas energy sector calculations, the U.S. GHGI tracks national GHG emissions from segments of the natural gas supply chain (as shown in the schematic of Figure 2), grouped as follows:

1. Production, gathering, and boosting ${ }^{13}$

2. Processing

3. Transmission and storage

4. Distribution.

The U.S. GHGI collects activity factor data from multiple natural gas-producing U.S. regions, but only emissions from the production, gathering, and boosting segments are calculated and reported in the U.S. GHGI for each of six natural gas-producing regions ${ }^{14}$ (EPA 2014a). National estimates of emissions from those segments are calculated as the sum of the emissions from each source category in each region. Emissions from the processing, transmission and storage, and distribution segments are tracked solely at the national level.

\footnotetext{
${ }^{11}$ Starting in 2015, countries are also required to report nitrogen trifluoride to the UNFCCC and may elect to report fluorinated ethers.

${ }^{12}$ There are subtleties to the split of emissions of methane from oil wells whereby certain emission sources are categorized in the natural gas and others in the petroleum sector. The interested reader can refer to the U.S. GHGI and its supporting Appendices for more information (EPA 2014a).

${ }^{13}$ Emissions from gathering and boosting are not always clearly differentiated from production in this grouped U.S. GHGI category.

${ }^{14}$ North East, Midcontinent, Rocky Mountain, South West, West Coast, and Gulf Coast.
} 
Methane emissions from the natural gas supply chain are the result of fugitive and vented sources across the supply chain. Fugitive emissions are unintended emissions from leaks; vented emissions are emitted by design such as from maintenance tasks or incomplete combustion of natural gas in engines. GHG emissions from so-called "beneficial uses" of natural gas, such as powering transmission equipment, are considered within the U.S. GHGI but not explicitly categorized for reporting. Combusting natural gas for these "beneficial uses" produces $\mathrm{CO}_{2}$ and small amounts of un-combusted methane that are tracked and reported separately in the U.S GHGI.

The U.S. GHGI reports net emissions for each of about 110 source categories within the natural gas industrial sector. EPA defines net emissions as potential emissions minus any emission reductions, as shown in Equation 1. Potential emissions represent emissions in the absence of controls. To account for controls, associated reductions are subtracted, as in Eq. 1 below. Emission reductions included in the calculation of net emissions result from existing voluntary or mandatory control measures.

Net Emissions $=$ Potential Emissions - Emission Reductions

For a few source categories, EPA estimates net emissions directly (e.g., gas well completions, liquids unloading) (EPA 2014a). These cases are rare largely due to a lack of emission factors for net emissions at the necessary levels of aggregation (both technologically and regionally). EPA has therefore relied upon available potential emission estimates for most source categories. Moreover, data on control practices (discussed below) that reduce potential emissions can be challenging to obtain at the source category and regional resolution of the U.S. GHGI, thus requiring the U.S. EPA to make simplifying assumptions or aggregate categories to calculate net emissions.

Potential emissions represent uncontrolled emissions from a given source category (a component type or activity), and are calculated by multiplying an emission factor (representing the mass of pollutant emitted per unit of activity) for potential emissions by the number of emission sources (called an activity factor) in that source category. Potential emissions are calculated as:

Potential Emissions $=\sum$ Emission Factor $x$ Activity Factor $\quad$ Eq. 2

An emission factor is a point estimate, typically an arithmetic average that is developed based on measurements of sources sampled within a source category. When estimates of certain source categories do not have emission measurements available, engineering approaches are utilized to develop an estimate based on proxies and assumptions. An emission factor has certain characteristics associated with it, including sample size (number of measurements), measurement method (including its associated measurement uncertainty), sampling design (e.g., stratification/classification, method used to select the sample), and treatment of measurements that are below the measurement detection limit. Methane emission factors used in the U.S. GHGI are mostly drawn from an EPA/GRI bottom-up measurement study ${ }^{15}$ conducted in the early 1990s and published in 1996 (Harrison et al. 1996). Harrison et al. (1996) measured emissions from a sample of sources from each segment of the U.S. natural gas supply chain. Recent studies

\footnotetext{
${ }^{15}$ Please see Section 4 text box for definition of this term.
} 
are starting to provide results that could be used to update the EPA/GRI emission factors (e.g., Lamb et al. 2015; Subramanian et al. 2015; Allen et al. 2015a; Allen et al. 2015b), as discussed further in Section 4.

Activity factors in the U.S. GHGI are estimated from a variety of surveys or other data sources, including the U.S. Energy Information Administration (EIA), the Oil and Gas Journal, DI Desktop powered by HPDI, and EPA's Greenhouse Gas Reporting Program (GHGRP) (EIA 2015; Oil and Gas Journal 2014; DI Desktop 2014; EPA 2014b). Some activity factors used in the GHGI are directly available; others are derived through calculations involving surrogates. For example, the activity factor used in the U.S. GHGI for pneumatic devices in the production segment is estimated by multiplying the number of wells by an estimate of the average number of pneumatic devices per well (i.e., not a direct count of pneumatic valves nationally). Because many source categories are inherently challenging to directly count, surrogate approaches are common within the GHGI and can involve complex, approximate or indirect methods.

The definition of emission reductions (Eq. 1) is shown in Equation 3, and is the sum of emissions reductions resulting from federal or state policies or regulation, plus those resulting from voluntary actions. Data on voluntary actions that reduce natural gas emissions are based on EPA's voluntary Natural Gas STAR program (EPA 2014c). Only those voluntary emission reductions reported to EPA are included in the U.S. GHGI. Estimates of emissions reductions from policies that reduce natural gas emissions are primarily based on analysis of the effects of two federal regulations (National Emission Standards for Hazardous Air Pollutants and New Source Performance Standards [EPA 2013a]).

\section{Emission Reductions $=$ Voluntary Actions + Policies}

The U.S. GHGI is continually assessed and improved. For instance, EPA annually reviews new scientific information and updates emission estimates in the inventory. The U.S. GHGI also annually undergoes a review by expert stakeholders, a 30-day public review, and then a review by an UNFCCC expert review team, which generates comments that result in further changes to the U.S. GHGI before it is published.

In recent years, increased attention has been placed on the methods used for estimating methane emissions from the natural gas supply chain in the U.S. GHGI. Through 2008, emissions factors had changed little since the early 1990s. However, beginning in 2009, the set of methods used to estimate emissions across the natural gas industry began to be revised and improved to account for industry development and new data sources. These changes have impacted emission estimates, and these updated emissions estimates are retroactively incorporated into estimates for prior years. ${ }^{16}$ For instance, EPA has switched to a direct emission calculation (i.e., rather than using equation 1) for completions with hydraulic fracturing and work-overs with hydraulic fracturing (i.e., refracturing), liquids unloading, condensate storage tanks, and centrifugal compressors (EPA 2014a).

\footnotetext{
${ }^{16}$ As methods for calculating emissions from a particular source category change, EPA recalculates emissions from all prior years using the revised methodology in order to make the time series consistent and comparable across years.
} 
For the 2015 U.S. GHGI, EPA implemented several changes as compared to previous U.S. GHGIs that were intended to improve inventory accuracy and representativeness (EPA 2015a), including:

- The data source and methods for estimating well counts

- Emission factors for hydraulic fracturing gas well completions and work-overs as well as offshore oil and natural gas

- The allocation of NG STAR program methane emission reductions to pneumatic controllers in the oil and gas sectors.

In addition, the GHGRP is a core part of EPA's plan for updating the U.S. GHGI (EPA 2015a). In 2009, the U.S. EPA published a rule requiring reporting of GHG emissions and supporting information from sources in certain industrial sectors emitting greater than 25,000 metric tons of $\mathrm{CO}_{2}$ equivalent emissions per year, including many types of facilities in the natural gas industrial sector. GHGRP includes data from over 2,000 facilities in the natural gas and petroleum energy sectors, beginning with data for the year 2011 (EPA 2015b). The GHGRP is used to provide a better understanding of facility-level GHG emissions sources and to guide emission reduction policies and programs. For example, GHGRP data was used in the 2013 U.S. GHGI to validate updates to emission estimates for liquids unloading. In addition, GHGRP data was used in the 2014 U.S. GHGI to update the methodology for estimating emissions from gas well completion with hydraulic fracturing with practice-specific net emission factors instead of potential emission factors.

Additional improvements using GHGRP data are being implemented for future U.S. GHGIs (EPA 2015a). In March 2015, GHGRP petroleum and natural gas systems facilities began reporting additional data to EPA. In many cases, these additional data were reported for years $2011,2012,2013$, and 2014, therefore providing four years of new data. The additional data includes, in some cases, equipment counts and other information that could allow for further improvements to the U.S. GHGI. EPA plans to review this new data reported to GHGRP for potential updates to methods across all segments of petroleum and natural gas systems. 


\section{U.S. Methane Emissions from the Natural Gas Supply Chain}

The natural gas infrastructure system in the United States is complex. For the purposes of inventory emissions estimates, this complex system is often divided into broad segments that serve specific functions (even if some functions are not present in certain regions). Figure 2 displays these segments schematically, along with U.S. GHGI (year 2012) estimates of net methane emissions (in $\mathrm{MMt} \mathrm{CO}_{2} \mathrm{e} / \mathrm{yr}$ ). Below is a list that describes the six segments of the supply chain, grouped as in the U.S. GHGI (i.e., the production segment is grouped with that of gathering and boosting; transmission is grouped with storage) (EIA 2014 and Skone 2014 except as noted):

1. Production; gathering and boosting

- Production of natural gas from wellheads or fields, comprised of $\sim 500,000$ existing gas wells, $\sim 40,000$ new gas wells drilled annually, and $\sim 6,300$ production companies (EPA 2014f).

- Gathering and boosting (compression) of natural gas from wellheads to a processing plant or to an interconnection with a larger pipeline. The U.S. natural gas gathering and boosting network includes $\sim 10,000$ gathering stations, which house $\sim 100,000$ gathering compressors and other equipment, and $\sim 200,000$ miles of gathering pipe.

2. Processing of natural gas in $\sim 580$ processing plants to extract natural gas liquids and remove impurities from the natural gas stream, as well as compress the natural gas to transmission line pressure.

3. Transmission and storage

- Transmission of natural gas through long-distance pipelines from the producing area to market areas (so-called "city gates") through $\sim 320,000$ miles of largediameter and high-pressure pipes and $\sim 9,000$ compressors. Transmission can be inter- or intra-state.

- (temporary) Storage of natural gas for future use in 400 underground facilities, including depleted oil and gas reservoirs, aquifers, and salt caverns. Storage also includes liquefied natural gas (LNG) storage infrastructure.

4. Distribution of natural gas from city gates to customers through $\sim 1,200$ distribution companies, $\sim 2.1$ million miles of small-diameter distribution pipes, and $\sim 62$ million homes with natural gas service lines. 

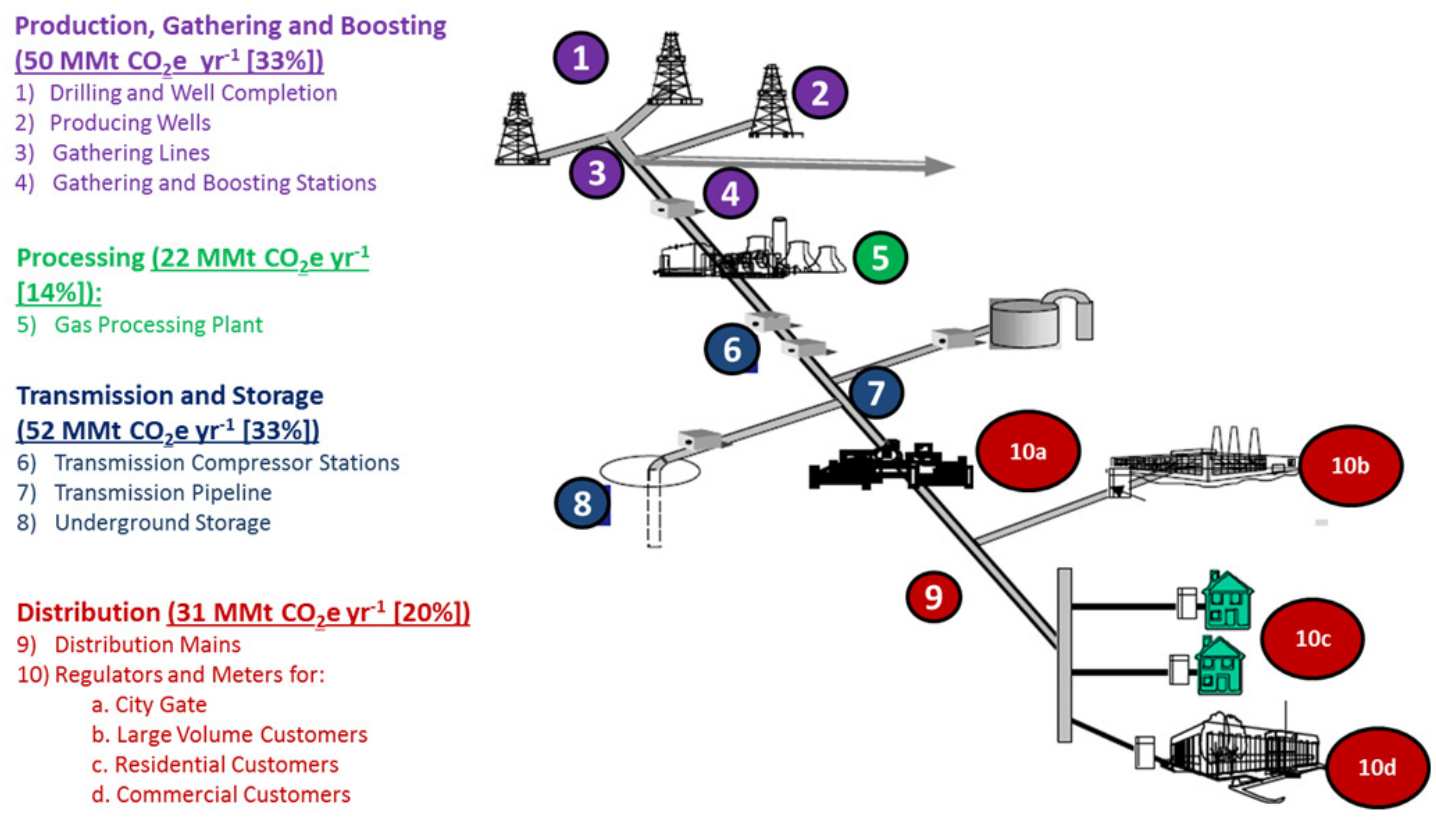

Figure 2. Organization of the natural gas supply chain into four segments. The figure also shows U.S. GHGI estimates of 2012 methane emissions from each segment and as a percentage of total natural gas sector methane emissions.

Source: Figure modified from EPA 2013b; data from EPA 2014a

The following analysis of methane emissions from the U.S. GHGI focuses mostly on the largest emission sources downstream of natural gas production. Production, gathering, and boosting remains one of the largest sources of methane emissions in the natural gas supply chain (Figure 2). Yet, for the last eight years, the U.S. GHGI reports that emissions from production, gathering, and boosting have been decreasing due to a combination of voluntary industry actions and government policies (EPA 2014a). Other segments within the natural gas supply chain are now estimated to contribute a larger portion of overall methane emissions from the natural gas sector.

The U.S. GHGI estimates that methane emissions downstream of production contributed more than $68 \%$ of the total emissions from the natural gas supply chain in 2012 (EPA 2014a). ${ }^{17}$ Emissions downstream of natural gas processing constitute approximately $53 \%$ of total emissions from the natural gas supply chain in 2012, with the majority of this amount from transmission and storage (EPA 2014a).

Across the entire natural gas supply chain, the U.S. GHGI estimates that $60 \%$ and $40 \%$ of emissions are fugitive and venting, respectively (EPA 2014a). Downstream of production, 78\% and $22 \%$ of emissions are estimated as fugitive and venting, respectively (EPA 2014a). Thus, the majority of methane emissions from the natural gas industry are from fugitive emissions, in particular from emissions downstream of production.

Figures A-1 through A-3 in Appendix A provide detail on the specific sources of emissions within each supply chain segment from production, gathering and boosting; processing; and

\footnotetext{
${ }^{17}$ We have phrased as "more than $68 \%$ " because gathering and boosting emissions are not quantified separately from production, yet are nevertheless downstream of production.
} 
transmission and storage, respectively. Tables A-1 through A-4 in Appendix A report how we used U.S. GHGI data to create Figures A-1 through A-3 and Figure 4.

Two observations from the 2014 U.S. GHGI are worth noting. First, our analysis of the U.S. GHGI reveals that the majority of the methane emissions downstream of production come from compressor stations. Emissions from compressor stations include venting and fugitives from compressor engines and those from other equipment and processes at compressor stations. ${ }^{18}$ Figure 3 illustrates the portion of total 2012 emissions released from compressor stations (or compressor engines alone when stand-alone compressors are utilized) in each of the four natural gas supply chain segments used by the U.S. GHGI. Although compressors account for only about $8 \%$ of emissions in the production, gathering, and boosting segment and none from distribution (because compressors are not used in distribution), EPA estimates that compressors account for $94 \%$ of emissions from the processing segment and in the transmission and storage segment, $79 \%$ of emissions are from compressor stations. As a result, approximately $43 \%$ of total emissions across the full natural gas supply chain are estimated to be emitted from compressor stations (inclusive of stand-alone compressors). Given the magnitude of the set of similar sources, efforts to reduce emissions from compressor stations could result in significant reductions across the entire supply chain, as has been suggested by EPA (2014f) and ICF (2014).

\footnotetext{
${ }^{18}$ The source categories are: miscellaneous station fugitive and vented emissions, centrifugal compressor fugitives (from wet seals and dry seals), reciprocating compressor fugitives (from rod packing), compressor engine exhaust (unburned methane), and compressor turbine exhaust (unburned methane).
} 


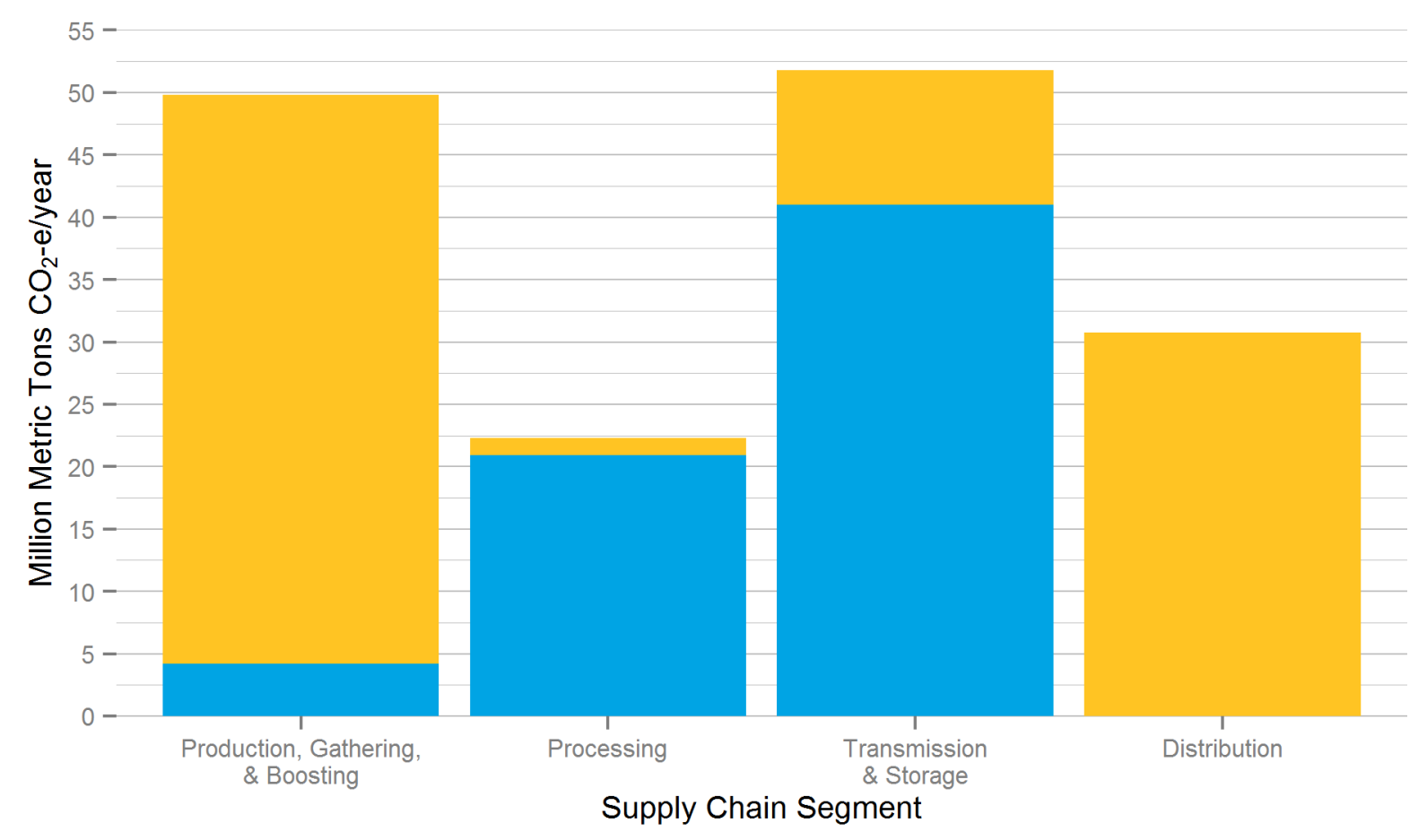

Compressor Stations All Other Sources

Figure 3. U.S. GHGI estimates of methane emissions from natural gas compressors within each supply chain segment in 2012. Our analysis of the U.S. GHGI reveals that compressors ${ }^{19}$ are the largest source of methane emissions in 2012 at processing plants, transmission stations, and storage facilities.

Source: EPA 2014a

Second, 2014 U.S. GHGI estimates that within the distribution segment, fugitive emissions comprise over $97 \%$ of total emissions, about half of which come from meters and regulators, and the other half from pipeline mains and service lines. ${ }^{20}$ Figure 4 illustrates the contribution of source categories to 2012 distribution segment emissions. In particular, leaks from cast iron and unprotected steel pipeline main and service lines are estimated to contribute $33 \%$ of total distribution segment emissions despite representing the fewest miles of any piping material (Table 1) (EPA 2014a). Cast iron and unprotected steel pipe and service lines have the largest emission factors per mile of pipe. Other types of main and service lines, such as plastic and protected steel, represent more miles of pipe and number of service lines, but are estimated to contribute only $17 \%$ of total emissions from the distribution segment given substantially lower emission factors. Compared to cast iron and unprotected steel pipe and service lines, reducing fugitive emissions from other types of main and service lines would require relatively larger changes to infrastructure (more miles) in order to achieve the same reductions in fugitive emissions.

\footnotetext{
${ }^{19}$ Compressor emissions in Figure 3 include U.S. GHGI categories of centrifugal and reciprocating compressor fugitives, compressor station fugitives and exhaust, compressor station pipeline fugitives, compressor engine exhaust, and compressor turbine exhaust.

${ }^{20}$ Service lines transport gas from a common source of supply to an end user's meter or piping.
} 


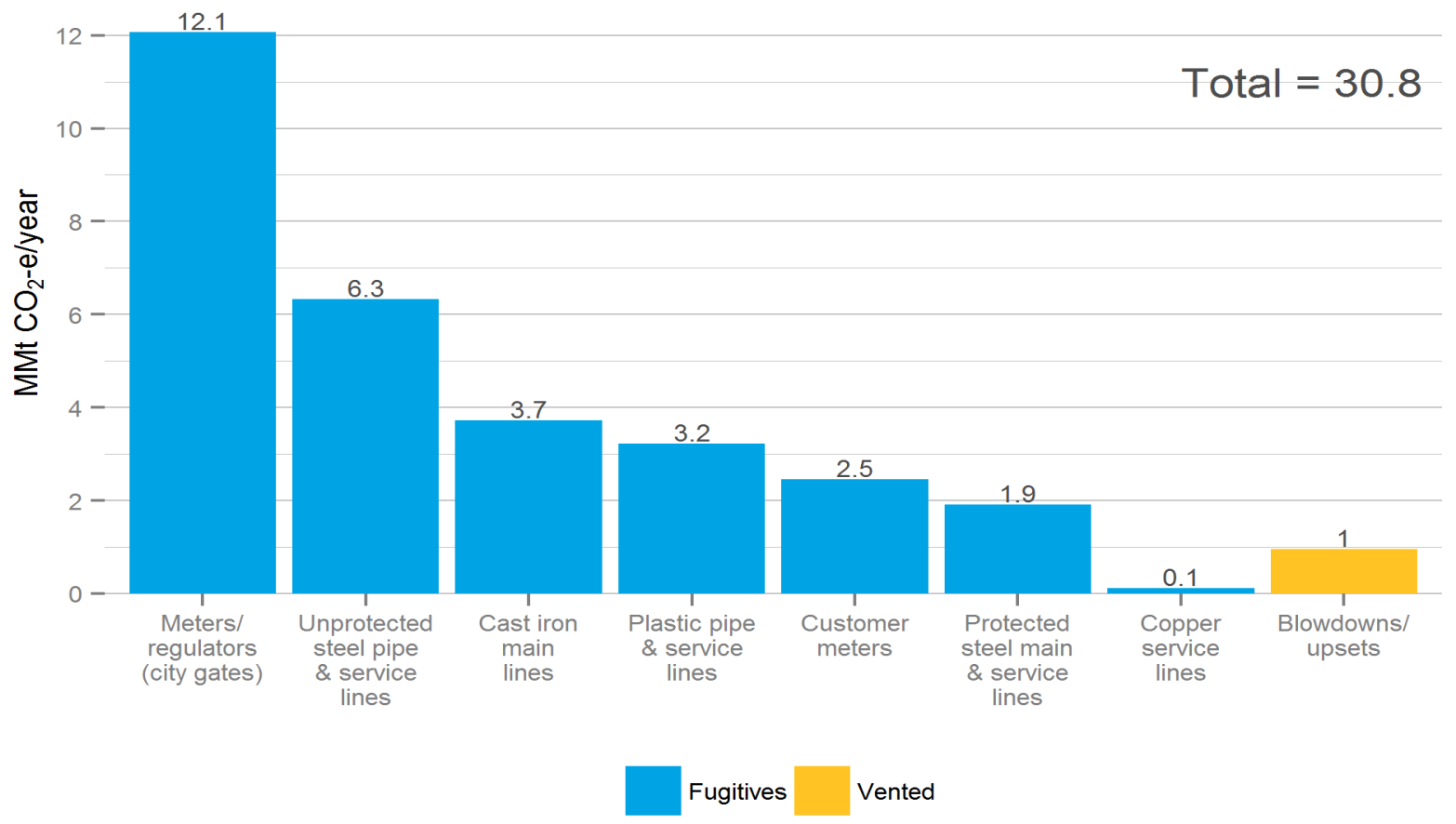

Figure 4. U.S. GHGI estimates of methane emissions from the U.S. natural gas distribution system in 2012

Source: EPA 2014a ${ }^{21}$

Table 1. U.S. Natural Gas Methane $\left(\mathrm{CH}_{4}\right)$ Activity Factor and Emission Factors in 2012 for Distribution Pipelines (Main Lines and Service Lines) as Reported in the U.S. GHGI

\begin{tabular}{|c|c|c|c|}
\hline Pipeline Category & Activity Factor & Emission Factor & Total Emissions \\
\hline Cast Iron Mains & $\sim 32,000$ miles & $240 \mathrm{Mcf} \mathrm{CH}_{4} /$ mile-yr & 7.7 million $\mathrm{Mcf} \mathrm{CH}_{4} / \mathrm{yr}$ \\
\hline Unprotected Steel Mains & $\sim 64,000$ miles & $110 \mathrm{Mcf} \mathrm{CH}_{4} /$ mile-yr & 7.0 million $\mathrm{Mcf} \mathrm{CH}_{4} / \mathrm{yr}$ \\
\hline Plastic Mains & $\sim 660,000$ miles & $9.9 \mathrm{Mcf} \mathrm{CH}_{4} / \mathrm{mile}-\mathrm{yr}$ & 6.5 million $\mathrm{Mcf} \mathrm{CH}_{4} / \mathrm{yr}$ \\
\hline Protected Steel Mains & $\sim 490,000$ miles & 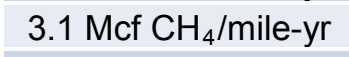 & 1.5 million $\mathrm{Mcf} \mathrm{CH}_{4} / \mathrm{yr}$ \\
\hline Unprotected Steel Service & 3.9 million services & 1.7 ${\mathrm{Mcf} \mathrm{CH}_{4} / \text { service }}$ & 6.6 million $\mathrm{Mcf} \mathrm{CH}_{4} / \mathrm{yr}$ \\
\hline Protected Steel Services & $\sim 15$ million services & $0.18 \mathrm{Mcf} \mathrm{CH}_{4} /$ service & 2.7 million $\mathrm{Mcf} \mathrm{CH}_{4} / \mathrm{yr}$ \\
\hline Copper Services & $\sim 1$ million services & $0.25{\mathrm{Mcf} \mathrm{CH}_{4} / \text { service }}$ & 0.25 million $\mathrm{Mcf} \mathrm{CH}_{4} / \mathrm{yr}$ \\
\hline Plastic Services & $\sim 45$ million services & $0.01{\mathrm{Mcf} \mathrm{CH}_{4} / \text { service }}$ & 0.45 million $\mathrm{Mcf} \mathrm{CH}_{4} / \mathrm{yr}$ \\
\hline
\end{tabular}

Source: EPA 2014a

\footnotetext{
${ }^{21}$ Figure 3 is created from aggregated U.S. GHGI data shown in Table A-4 in Appendix A.
} 


\section{Challenges to Constructing the U.S. GHG Inventory}

All inventories, including the U.S. GHGI, rely on measurements in combination with estimates of the quantity of emissions from myriad sources and aggregate these emissions values to various regional or sectoral levels. Direct measurement of the quantity of emissions from every source would be infeasible given the vast number of sources, so inventories must rely on statistical approaches to calculating the emissions quantities. As with any statistically-based calculation, there is an inherent level of uncertainty associated with the results. Given that the U.S. GHGI is leveraged for a variety of regulatory, institutional, and academic purposes, it is crucial to understand the challenges in constructing the U.S. GHGI so it can be properly interpreted and to explore opportunities for improvement to the accuracy and reliability of its estimates. Although this section focuses on the U.S. GHGI, many of the challenges are applicable to other inventories to the extent they use similar methods.

Given the importance of methane as a climate-forcing agent as well as the desire to understand emissions implications from the rapidly changing natural gas and oil industry in the United States, researchers have conducted analyses comparing various measurement-based estimates of methane emissions rates (See Text Box 4-1 for definitions of top-down and bottom-up studies, including measurement studies and inventories) and those that use inventory-based estimates of emissions rates. Brandt et al. (2014) synthesized more than 20 years of such emissions measurements from North America, wherein results of numerous prior studies were compared to corresponding results from GHG inventories, which included but were not limited to the U.S. GHGI. This synthesis included measurements taken at numerous scales, from individual components to entire continents, using a variety of methods.

Brandt et al. (2014) found that estimates of methane emissions from inventories were consistently (though not exclusively) ${ }^{22}$ lower than those estimated through measurement techniques (see Figure 5). For studies conducted at the scale of regions or larger, Brandt et al. (2014) reported that measured emissions were generally 50\% higher than those based on the U.S. GHGI, with a range of 25 to $75 \% .{ }^{23}$ The authors were not able to specifically quantify the contribution of methane emissions from natural gas systems to this total underestimation. However, they noted that available evidence suggests that the natural gas supply chain contributes to the underestimation, but likely does not account for all of the underestimation observed.

\footnotetext{
${ }^{22}$ It should be noted that at smaller spatial scales (e.g., at facilities and components) some ratios of measurement to inventory estimate (which were emission factors at the component level) were found less than one (i.e., measurement $<$ inventory estimate), although a substantial majority were greater than one.

${ }^{23}$ Not all studies originally compared their measurement-based estimate to the U.S. GHGI; Brandt et al. adjusted each study's comparison to consistently use the U.S. GHGI, appropriately scaled to the same year, spatial domain and included sectors.
} 


\section{Text Box 4-1. Defining Top-down and Bottom-up Studies}

The measurement studies and inventories discussed in this report are divided into those that employ "top-down" and "bottom-up" approaches. The following definitions are used in this paper, with a warning to readers that the delineation between study types can vary between authors.

Top-down studies are those that measure ("in-situ", or within the air mass) or estimate (e.g., from satellite remote sensing) the concentration of methane in the atmosphere, and then use different modeling approaches to estimate mass flux (mass of methane emitted per unit time and area) from observed or estimated concentrations. Typically, top-down studies measure gross methane flux rate within the experimental area of study. Measurements taken from airborne platforms, such as planes or satellites, have more limited spatial resolution than those taken from ground-based platforms, such as vehicles or stationary towers. Attributing flux estimated through measurements to specific sources or classes of equipment can be challenging.

Bottom-up studies take a disaggregated approach to developing estimates of emissions at the level of individual sources and source categories. Inventories and life cycle assessments are two common types of bottom-up modeling studies, each employing different system boundaries and scaling approaches in engineering-based calculations to estimate emissions from a set of components or activities to represent emissions of a defined population (e.g., pneumatic valves or shale gas well completions). Inventories are the focus of this report; life cycle assessments are discussed thoroughly in Heath et al. (2014a) and contrasted with inventories in Heath et al. (2014b). Bottomup inventories sum GHGs emitted or removed from the atmosphere over a period of time from a specific set of components, activities, or facilities within a geographic region of interest.

Bottom-up measurement studies measure flux directly from individual components, activities, or facilities that are then used to estimate inventories. Although attributing emissions to a specific source is often easier in bottom-up measurement studies compared to top-down measurement studies, the populations of sources from which samples are measured by bottom-up studies can be large. When sampling from large source populations, it can be challenging to establish a representative sample with enough statistical power to reliably characterize the full distribution of the emissions source category. Measurement techniques that only measure concentration can be useful for assessing safety risk or identifying leaking components, but only provide a qualitative assessment of mass flux (e.g., Phillips et al. 2013). Some studies measure concentration only while others measure both concentration and mass flux. Studies that measure mass flux are generally more useful for updating inventories.

When considering both top-down and bottom-up types of studies, and especially when comparing them, it is important to consider the spatial and temporal scales of each. Studies can span a range of scales from specific components to continents, and measurements can occur over timescales of minutes to years. It is also important to consider the scope of emission sources assessed and whether there could be multiple source sectors contributing to the measured emissions. Note that while more commonly an issue for top-down studies, this challenge can also exist for bottom-up studies. For example, which components' emissions are routed to a common vent stack being measured or does the inventory estimate exclude certain emission sources that would be emitting in the zone of measurement? There are a host of other important factors critical to the proper interpretation and use of measurement study results, such as the year of study, the vintage of the equipment measured in the study, and the accuracy of the measurement method employed. 


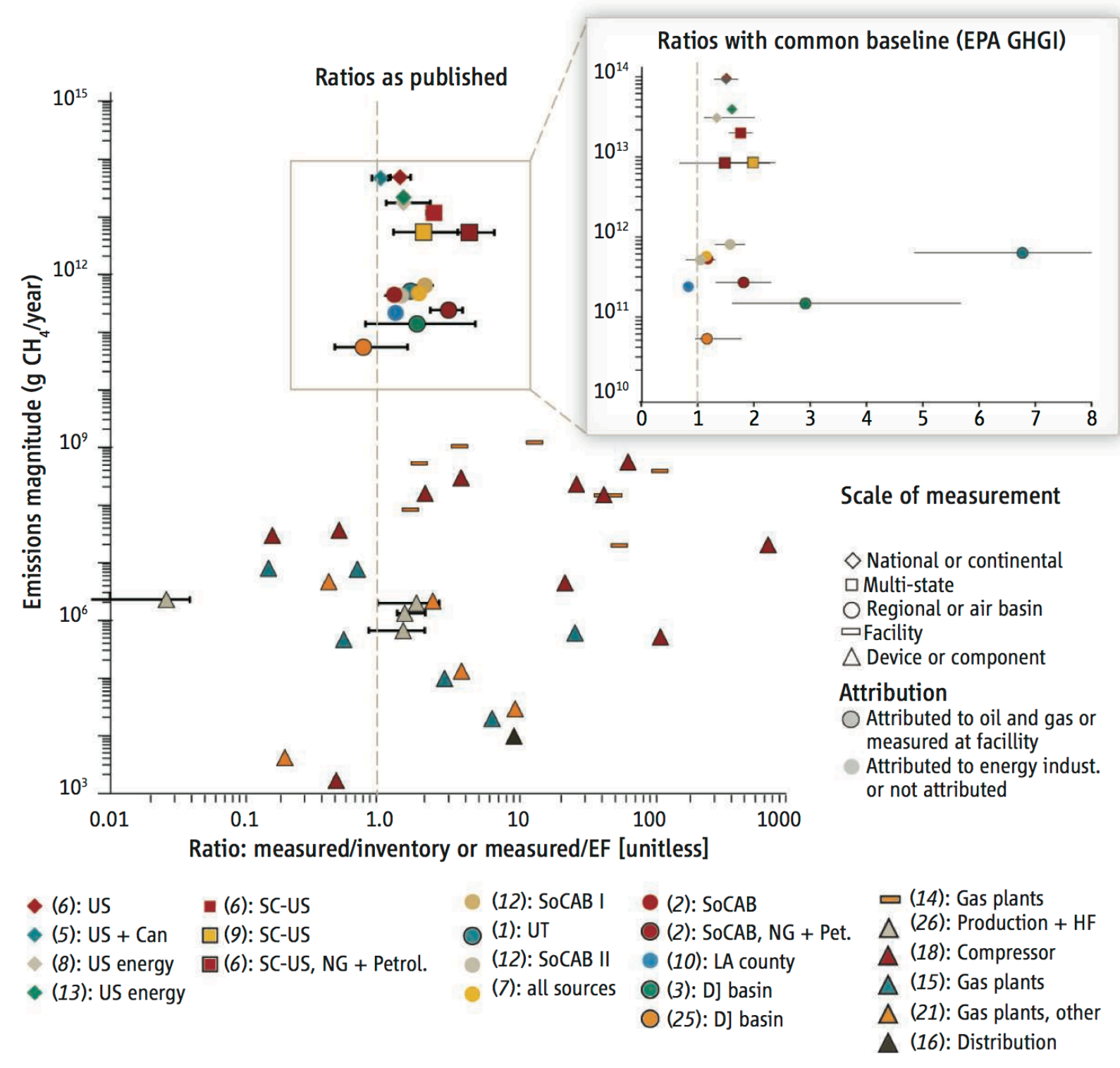

Figure 5. A recent synthesis of methane emission measurements that were compared to inventory estimates of methane emissions, which found that inventory-based estimates have consistently underestimated measured emissions across a wide range of measurement scales, locations, source categories and years. Ratios greater than one in the plot indicate measured emissions are larger than expected from emission factors or inventory estimates. Given that some studies compared their results to inventories other than the U.S. GHGI, the figure inset adjusts published comparisons to consistently compare measurements to the U.S. GHGI, scaled to the year of study and, in some cases, the sector under examination. Multiple points for each study (designated by different marker types) correspond to different device classes or different cases measured in that study.

Source: Brandt et al. 2014

Inaccuracy and uncertainty in both measurement and inventory studies could be contributing to the discrepancy observed between measured methane emissions and inventory-based estimates. However, given the focus of this report on inventories, we explore the challenges (and potential sources of uncertainty) associated with inventories, with particular attention to those relevant to 
the U.S. GHGI, that could at least partly explain this discrepancy. The level of accuracy of emission estimates used in inventories depends upon three key criteria (Brandt et al. 2014):

1. All sources of emissions relevant to the inventory are assessed.

2. The sample of sources used to construct emission factors are representative of the emitting source categories assessed in the inventory.

a. Samples are from, or can represent, the time period covered by the inventory.

b. Sample sizes are sufficiently large and diverse to capture the variability in emissions that exists within source categories.

c. The point estimates of a distribution of emission measurements for a given source category are unbiased and consider the shape of the distribution of available emission estimates.

3. Activity factors (counts) are complete and accurate.

The purpose of this analysis is to offer perspectives for understanding the challenges of successfully meeting these criteria, as well as to suggest pathways to advance knowledge that can improve inventory accuracy and representativeness (Section 5); some of these suggestions may already be under consideration by EPA in developing the U.S. GHGI.

\subsection{Inventory Completeness}

Assessing all sources of emissions is crucial to ensuring that the inventory provides an accurate representation of total U.S. methane emissions. In some cases, there are no estimates of emissions because knowledge to quantify emissions from such sources is not available. Brandt et al. (2014), ICF (2014), and EPA (2014a) identify a small number of sources of methane emissions from natural gas and oil systems that currently are not included within the U.S. GHGI, and may potentially be excluded from other inventory estimates:

- Abandoned wells and other derelict infrastructure

- Emissions measurements on gathering pipelines

- Emissions of methane dissolved in produced water that is released from management of produced water, e.g., retention ponds ${ }^{24}$

- Management of solid waste from natural gas operations, including land application

- Well work-overs that are not recompletions ${ }^{25}$

- Well testing.

\footnotetext{
${ }^{24}$ Methane entrained in produced water is estimated within the U.S. GHGI for completion flowback, liquids unloading and from ongoing water production in coal bed methane wells in two states (AL and WY). Dissolved methane takes longer to evolve and emit; some states have regulations that would require control of these emissions, so emissions estimates would need to be developed considering those regulations.

${ }^{25}$ All well work-overs are categorized as recompletions in the U.S. GHGI. However, work-over activities other than recompletions such as well bore maintenance can also be performed, which could release methane and may have different methane emission factors than for recompletion. In addition, it is not clear that well workovers other than recompletion are included in the activity factor methods used in this U.S. GHGI source category.
} 
Emissions of natural gas that are under the control of the end user (e.g., in industrial facilities or feeder lines), but occur prior to end use combustion, are not classified under the natural gas supply chain in the U.S. GHGI. Only emissions up to an end user's meter or off-take point are considered a part of the natural gas supply chain. In addition, some of these emissions are also not included in the U.S. GHGI, and potentially also for other inventories. In the U.S. GHGI, an estimate of emissions of methane from incomplete combustion is included in the applicable end use sector's GHG emissions (e.g., residential, commercial, vehicles), but emissions from sources like leaking pipes, valves and flanges that exist on the natural gas consumer's site are not included. These additional potential sources of fugitive methane emissions are understudied and their magnitude and frequency has not yet been quantified. (One study suggesting potential importance of this source category is Wennberg et al. [2012]).

\subsection{Inventory Representativeness}

Uncertainty and inaccuracy in inventories can result from a lack of representativeness of the samples used to construct emissions factors for inventories. For example, the age of the equipment sampled in the original EPA/GRI bottom-up measurement study (which is the source of most emission factors used in the U.S. GHGI) (Harrison et al. 1996) may differ from equipment currently used. There is a potential relationship between age of equipment and emissions. A variant of this issue is how technologies can evolve over time in their design and use; emission factors for older equipment may not represent those for current ones. This issue can be addressed by sampling modern populations of equipment in their current usage patterns and developing updated emission factors from these new data.

A strong sampling strategy can help to ensure representativeness of the samples used to construct emissions factors for inventories. In order to create a sample that is useful in improving inventories, it is critical both to sample across the range of key influencing factors of emissions, such as:

- Equipment type

- Equipment age

- Degree of maintenance

- Duty cycle 26

- Operator practices

- Emissions controls in place.

Also, it is important to consider regional differences that may also affect emission rates. Some sources of regional variation include:

- Regulatory jurisdictions and the differences in requirements between them

- Regional gas price that can influence how natural gas infrastructure is utilized and developed

${ }^{26}$ Proportion of time a component, device, or system is operated. 
- Geologic factors, such as gas composition, water-to-gas ratio or the gas-to-oil ratio, and the type of gas being extracted (shale gas, tight gas, conventional gas, or coal bed methane) that can influence the use of certain technologies and practices

- Age of infrastructure that can depend on when a play was developed amongst other factors

- Market concentration and capitalization of operators

- Climate of the infrastructure location such as temperature, elevation, and relative humidity.

While regional information is inherent in the data sources used in the U.S. GHGI (e.g., samples for emission factors taken in different regions, regional activity information), the U.S. GHGI does not report regionally disaggregated emission estimates except in some specific cases. To wit, the U.S. GHGI includes six natural gas-producing regions only for production, gathering, and boosting. Other supply chain segments are assessed nationally.

Another concern regarding representativeness of samples is whether facilities whose emissions are sampled were chosen at random from the full target population. Sampling bias can occur if a random sample is not achieved. Sampling bias is the systematic undersampling or non-sampling of sources that have emission profiles different than those sources sampled to represent a source category.

Acquiring a truly random sample of industrial facilities is challenging owing to, for instance, issues of access. A requirement for measuring emissions from a particular component of natural gas infrastructure is to have access to that component. Those conducting scientific studies generally lack the authority to require access to industrial facilities in the oil and gas sector, and thus are limited to measuring facilities whose owners have volunteered a facility to be measured. ${ }^{27}$ In addition, safety requirements for visitors to industrial facilities necessitate some degree of advance notice. Questions have been raised as to whether any changes to normal operation were made prior to the emission measurement. It is not possible to prove sampling bias or measure the degree of sampling bias without access to the non-sampled population, which is obviously a challenging undertaking given the aforementioned access restrictions. Yet, the authors are unaware of a study that has accomplished a truly random sample of the full population of target source category.

Recent measurement studies on several types of emissions sources suggest that emissions from a small number of sources represent a large fraction of total emissions from that source category, creating the so-called "fat tail" distribution of emissions rates (e.g., Allen et al. 2013; Allen et al. 2015a; Allen et al. 2015b). The main concern in this context is undersampling for any given source category; smaller samples are unlikely to capture the rare tail of the distribution. Undersampling of the tail increases the likelihood that the mean of the sample will be downwardly biased relative to the mean of the true population (Brandt et al. 2014). In other words, the mean of the sample will underestimate the emissions from the source category.

\footnotetext{
${ }^{27}$ The authors are only aware of one study that used compulsory sampling, which was required by the City of Fort Worth. This bottom-up measurement study sampled a large number of natural gas operations in the Barnett shale of Texas (Eastern Research Group 2011).
} 


\subsection{Activity Factor Data}

Most of the public and scientific attention toward improving inventories has been focused on improving emissions factors. However, activity factors are also critical to ensuring accurate and unbiased inventory estimates of emissions, and therefore also should be carefully evaluated and strategies for improvement considered. Analogous to the census of the U.S. population, direct counting of all natural gas emission sources is not possible, so activity factors are estimated using a variety of data sources and methods. EPA has improved accounting of wells and completions and identified other areas for improvement of activity factors (EPA 2015a). It is likely that counts of other source categories could benefit from improvement (EPA 2014a).

\subsection{Uncertainty Quantification}

Another challenge with current inventories is in robust uncertainty quantification. Emissions cannot be estimated with 100\% accuracy; there is inevitable uncertainty. Uncertainty quantification not only lends credibility to estimation efforts, but can inform decision makers about relative confidence and help focus inventory improvement efforts for instance through an uncertainty importance analysis.

Uncertainty quantification is part of rigorous reporting of measurements of methane emissions, and should likewise be robustly reported along with inventory estimates to enable meaningful comparisons. It is challenging to quantify the uncertainty of all input parameters to an inventory, but this should not deter vigorous efforts to do so. In fact, this endeavor will become more viable in the near future, enabled by recent or soon-to-be available bottom-up measurement studies (such as those shown in Figure 6); one of the goals of these recent studies has been to rigorously estimate and report uncertainty. Most efforts today include development and reporting of the full distribution of emission estimates which can be used to update the distributions employed in uncertainty quantification of inventories. Uncertainty quantification also requires robust information about distributions of activity factors and other sources of uncertainty.

For several years, the U.S. GHGI has employed a Monte Carlo uncertainty quantification framework using IPCC-recommended Tier 2 methods (IPCC 2006). ${ }^{28}$ It is focused on evaluating parametric uncertainty, considering twelve major emission source categories ${ }^{29}$ that account for $92 \%$ of total methane emissions from the natural gas supply chain. The ranges and distributions tested for emission and activity factors are informed by empirical data and expert judgment; ${ }^{30}$ the latter is especially relied upon in the case of activity factors. Parametric uncertainty (e.g., uncertainty in the emission and activity factors) is not the only source of uncertainty. There is also methodological uncertainty. Whereas U.S. GHGI methods have changed over time, the reported uncertainty range has not been updated since 2010 (EPA 2011; EPA 2015a). EPA plans to eventually update the U.S. GHGI uncertainty distributions (EPA 2015a).

\footnotetext{
${ }^{28}$ Baseline methane emissions for 2012 were 6.2 MMt methane and EPA's uncertainty analysis reports the $95 \%$ confidence interval for methane emissions as $5.0(-19 \%)$ to $8.0(+30 \%)$ MMt methane.

${ }^{29}$ Though the number of source categories examined in its uncertainty analysis is reported, which categories were selected is not.

${ }^{30}$ The emission factor ranges, employing normal, lognormal, uniform, triangular, or beta probability distributions, are based on a combination of information documented in different data sources (e.g., EPA/GRI [1996] and EIA [2015]) and expert judgment.
} 


\section{Recommendations for Improvements to the U.S. GHGI Leveraging Bottom-up and Top-down Studies}

By providing a high level of granularity and repeatability, inventories have been a critical foundation for informing source category prioritization. Inventories, especially the U.S. GHGI, have been frequently used in research and development as well as emissions reduction decision making. It will be important to leverage recent and forthcoming studies to maintain the functions of inventories and address the many challenges to inventory accuracy in a rapidly evolving industrial sector such as natural gas. This section focuses specifically on opportunities for improvement to the U.S. GHGI; to the extent other inventories use similar structure, data sources, and methods, the suggestions made here could be relevant to their improvement as well.

As defined in Text Box 4-1, studies that can help to inform and improve the U.S. GHGI come from both top-down and bottom-up perspectives. Leveraging the multitude of these studies will benefit from careful analysis of any differences in design, scope and scale of each study. For context, Text Box 5-1 displays a summary of published top-down and bottom-up measurement studies.

Bottom-up measurement studies provide estimates of emissions from particular categories of components, activities, or sites that can be used to develop or update the emission factors used in inventories. To easily do so, bottom-up studies should align either with existing inventory source category definitions or with available activity factor data. Top-down studies can help assess the accuracy of inventory estimates, though direct comparisons between these two forms of emissions estimates can be challenging. For instance, studies can be conducted at different spatial and temporal scales, and represent different sets of emission sources. Currently, top-down studies come at a high degree of emission source aggregation (i.e., representing emissions from a set of sources and sectors), providing limited feedback as to emission source category prioritization. Advances in downscaling top-down emission estimates have the potential to enhance the ability of top-down studies to aid inventory verification efforts.

To elaborate on the sectoral alignment issue, inventories including the U.S. GHGI typically categorize emissions by industry sectors, such as oil or natural gas. Similarly, the regulatory system in the United States is organized by industry sector, and thus inventory allocation of emissions to industrial sectors is necessary to support policy and regulatory decisions. However, hydrocarbons exist along a continuum of gaseous to liquid, often in the same geologic formation, making the task of categorizing a particular emission source as either in the oil or natural gas industrial sector challenging and arbitrary, with no consensus definition. This challenge is increasing as investment in liquids production (condensates, natural gas liquids, and oil) grows, increasing the scale of multi-product systems. Categorization of emissions by industry sector in locations where both are present creates challenges in allocating measured emissions to oil or 
natural gas products, and also for the comparison of resulting measurements to an appropriate set of inventory source categories. ${ }^{31}$

\section{Text Box 5-1. Top-down and Bottom-up Studies}

Both top-down and bottom-up measurement studies can support inventory improvement, but in different ways. Figure 6 displays the locations of an exemplary set of 37 published measurement studies representing different segments of the U.S. natural gas supply chain. Many more studies are ongoing (e.g., EDF 2014). See section 7 for the numbered reference list of Figure 6.

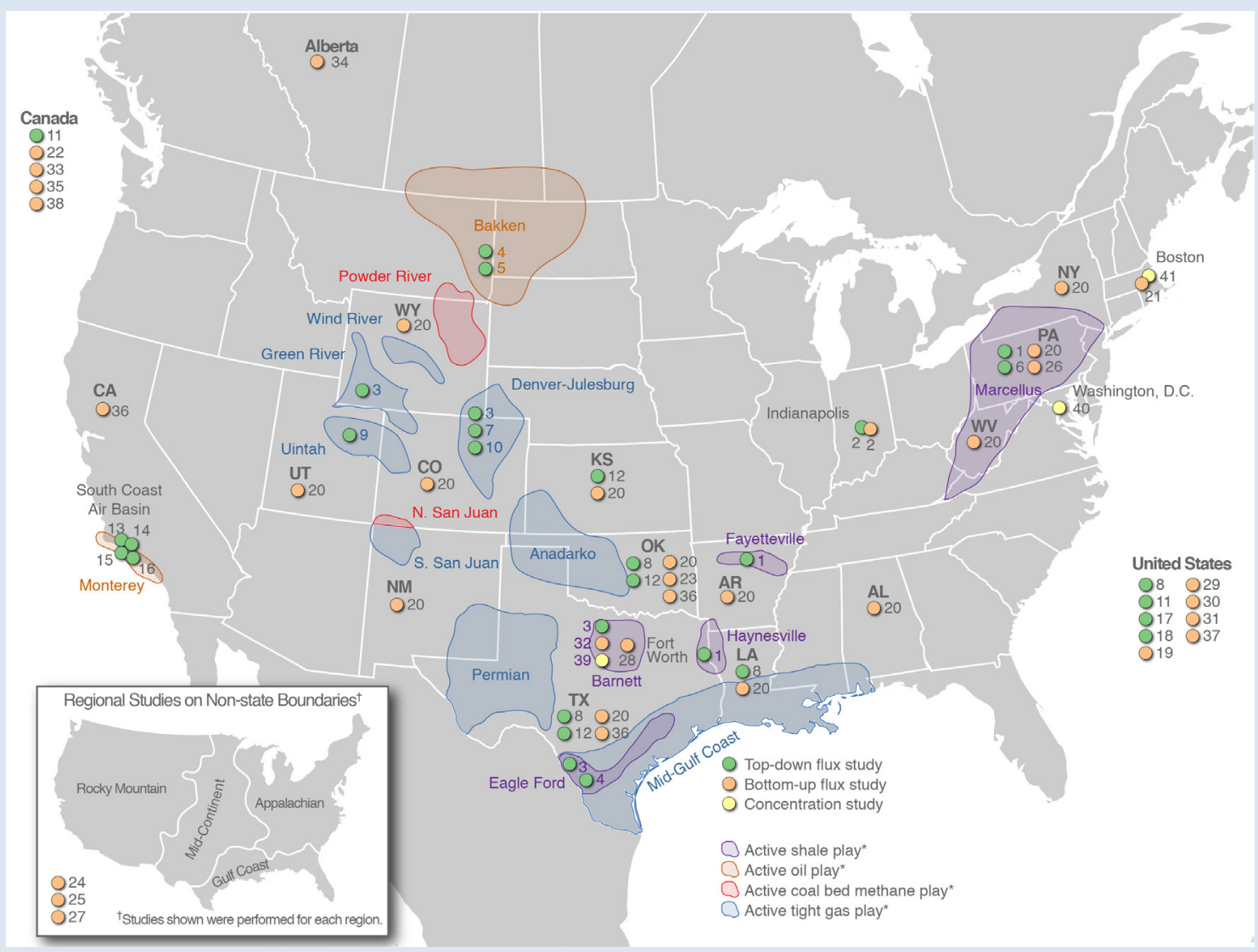

Figure 6. Mapping of exemplary methane emission measurement studies published through February 2015 by type and location. See Section 7 for the numbered reference list. National studies and those not specific to a basin within a multi-state (AAPG-CSD) region are listed to the sides of the map under "United States" or "[region name]" headings. Studies conducted within unspecified areas within a named state are listed underneath the 2-letter state code. The portions of the natural gas supply chain covered by the studies are: production, boosting, and gathering: 20, 2229, 33, 36-39; transmission, storage, and processing: 2, 19-21, 29, 31-39; and distribution: 2, 21, 30, 36, 37, 40, 41. [AAPG-CSD = American Association for Petroleum Geologists-Committee on Statistics of Drilling.]

*Only active plays relevant to current and known forthcoming studies are shown (Oil and Gas Journal 2014).

\footnotetext{
${ }^{31}$ It should be noted that the U.S, EPA (2015a) has updated its methods for allocation. The 2014 U.S. GHGI (EPA 2014a) categorizes GHGs emitted from oil wells also producing natural gas (i.e., associated gas wells) within the oil sector using the World Oil Magazine outlook for producing wells (2013). A revision for allocation in the 2015 U.S. GHGI (EPA 2015a) is to use a gas-to-oil production ratio greater than $100 \mathrm{Mcf} / \mathrm{bbl}$ to determine if a well is a gas wells rather than an oil well.
} 
EPA has stated its intention to evaluate new studies of methane emissions as they become available, as well as leverage resources collected through related EPA programs such as the GHG Reporting Program. In addition, inventory improvement efforts, such as those outlined in the President's FY16 budget announced on January 14, 2015 (White House 2015), have the opportunity to improve the U.S. GHGI. Based on examination of available evidence and of current challenges to both bottom-up and top-down studies (Figure 6) as well as considering assumptions and limitations of inventories first described in Brandt et al. (2014), we identify a set of opportunities for improvement to estimates of methane emissions from the U.S. GHGI, organized by type of study. Again, to the extent other inventories use similar structure, data sources, and methods, the suggestions made here could be relevant to their improvement as well. These recommendations can offer guidance for agencies, researchers and research-sponsoring organizations to consider when evaluating inventory improvement opportunities as well as designing studies that can help enhance inventory accuracy.

\section{Bottom-up Measurement and Inventory Studies}

1. Studies that fill known, prioritized gaps in current knowledge of natural gas-related methane emission sources, such as abandoned wells or measurements on gathering pipelines, can improve inventory completeness and accuracy. Another gap is leakage of natural gas after it is transferred to the end user, which at least one study (Wennberg et al. 2012) suggests could be an important source of anthropogenic methane emissions.

2. Studies that update emission factors for priority source categories can improve inventory accuracy. Prioritization considerations could include the degree of technological change since previous emissions factors were developed and contribution to total natural gas sector emissions.

3. Accounting for variability of emission factor for sources within an emission source category, regional variation, and "fat tail" distributions requires enhanced bottom-up measurement study sampling strategies and inventory methods. Researchers and study sponsors should consider how to ensure robust sample size, strong sampling design to capture source variability and minimization of self-selection bias. Robustly incorporating heavily-skewed distributions in inventory methods could be advanced through statistical research on the quantitative methods underpinning inventories.

4. Inventory utilization of bottom-up measurement study results can be enhanced if the study has been designed to produce results that align with the existing inventory structure. Conversely, results from new studies might indicate areas where inventory structure could change to better reflect the latest insights regarding emission sources.

5. Activity factor accuracy can be improved by leveraging existing data sources (such as EPA's GHGRP) or developing new data sources that can accurately, completely and directly (e.g., limiting use of surrogates for the activity) describe the industry's activity. One consideration for changes in activity factor methods is how to maintain a consistent time series such that trends can be consistently assessed, balanced by the need to improve accuracy for today's emission estimates. Another is to develop the empirical foundation for activity factor uncertainty estimation.

6. Transparency and credibility of inventory estimates can be improved by bolstering uncertainty quantification of inventory models, including development of uncertainty assessment for emission and activity factors as methods change over time. Improving 
inventory estimates of uncertainty relies on robust uncertainty estimates from the underlying emission and activity factor studies.

7. Opportunities exist to enhance the inventory or develop derivative products to more easily align spatially, temporally and sectorally with atmospheric measurements. Such an effort could yield an improved validation function of top-down measurement studies. For instance, separating gathering systems from the production segment ${ }^{32}$ in inventory accounting and coordinating estimates of emissions from co-product systems such as colocated oil, liquids, and condensate production activities could improve alignment of inventory estimates to where, when and from what physical sources emit in the atmosphere. Developing a gridded inventory product, especially in conjunction with the aforementioned suggestions, could greatly improve the ability of top-down measurement studies to more accurately compare their results to those from the inventory.

\section{Top-down Measurement Studies}

8. A key research need for top-down measurement studies is to improve and validate methods for attributing total methane concentrations in the atmosphere to their source, such as distinguishing between biogenic and fossil sources and then amongst the many fossil sources like coal, natural gas, and oil. Additionally, to aid in the attribution process, research is needed to better understand methane emissions from non-oil and gas sources. For instance, natural sources like geologic seepage share the same isotopic signature as anthropogenic fossil sources, and thus can confound attribution of fossil methane to fossil fuel infrastructure.

9. Another key research need for top-down measurement studies is strengthening methods to downscale the resolution of atmospheric measurements to those for specific sources such as individual facilities. Such advances can enhance the capability of top-down measurement studies to quantify emission source strength, variability, and prioritization within a certain geographic area. One approach to achieve this goal is through pairing top-down and bottom-up measurement studies using various methods in the same region to leverage advantages of both approaches (e.g., comprehensive coverage through topdown measurements, detailed emission source specification through bottom-up measurements) and gain confidence in the ability of top-down methods to reflect emissions quantified directly.

\section{Integration of Bottom-up and Top-down}

10. Significant benefit could be gained for both bottom-up inventories and top-down measurements if they could be contemporaneously and systematically coordinated with aligned system boundaries (spatial, temporal and sectoral). Such an effort could reduce the consistent gap found by Brandt et al. (2014) between measurements and inventories; move toward the goal of top-down measurement studies capable of verification of inventory estimates of emissions; and increase confidence in inventory methods and their results that are used for policy and industrial decision making.

\footnotetext{
${ }^{32}$ Proposed reporting rules in the GHGRP for gathering systems may help this differentiation of gathering and boosting if enacted (Federal Register 2014).
} 


\section{References}

Allen, D.; Torres,V.M.; Thomas, J.; Sullivan, D.W.; Harrison, M.; Hendler, A.; Herndon, S.C.; Kolb, C.E.; Fraser, M.P.; Hill, D.; Lamb, B.K.; Miskimins, J.; Sawyer, R.F.; Seinfeld, J.H. (2013). "Measurements of Methane Emissions at Natural Gas Production Sites in the United States." Proceedings of the National Academy of Sciences 110(44). Accessed December 2014: http://www.pnas.org/content/110/44/17768.abstract.

Allen, D.; Sullivan, D.; Zavala-Araiza, D.; Pacsi, A.P.; Harrison, M.; Keen, K.; Fraser, M.P.; Hill, D.; Lamb, B.K.; Sawyer, R.F.; Seinfeld, J.H. (2015a). "Methane Emissions from Process Equipment at Natural Gas Production Sites in the United States: Liquid Unloadings." Environmental Science and Technology 49(1); pp. 641-648. Accessed January 2015: http://pubs.acs.org/doi/abs/10.1021/es504016r.

Allen, D. Pacsi, A.P.; Sullivan, D.; Zavala-Araiza, D.; Harrison, M.; Keen, K.; Fraser, M.P.; Hill, D.; Sawyer, R.F.; Seinfeld, J.H. (2015b). "Methane Emissions from Process Equipment at Natural Gas Production Sites in the United States: Pneumatic Controllers." Environmental Science and Technology 49(1); pp. 633-640. Accessed January 2015: http://pubs.acs.org/doi/abs/10.1021/es5040156.

Bradbury, J.; Obeiter, M.; Draucker, L.; Stevens, A.; Wang, W. (2013). Clearing the Air: Reducing Upstream Greenhouse Gas Emissions from U.S. Natural Gas Systems. Washington, D.C.: World Resources Institute (WRI). Accessed

November 2014: http://www.wri.org/publication/clearing-air.

Brandt, A.R.; Heath, G.A.; Kort, E.A.; O’Sullivan, F.; Pétron, G.; Jordaan, S.M.; Tans, P.; Wilcox, J.; Gopstein, A.M.; Arent, D.; Wofsy, S.; Brown, N.J.; Bradley, R.; Stucky, G.D.; Eardley, D.; Harriss, R. (2014). "Methane Leaks from North American Natural Gas Systems." Science 343:6172; pp. 733-735. Accessed October 2014: http://www.sciencemag.org/content/343/6172/733.full.

Department of Energy (DOE). (2015). The Quadrennial Energy Review: Energy Transmission, Storage, and Distribution Infrastructure. DOE. Accessed June 2015: http://energy.gov/epsa/quadrennial-energy-review-qer.

Eastern Research Group, Inc. and Sage Environmental Consulting, LP. (2011). City of Fort Worth Natural Gas Air Quality Study. Prepared for the City of Fort Worth. July 13, 2011. Fort Worth TX

Environmental Defense Fund (EDF). (2014). Gathering facts to find climate solutions. Accessed January 2015: https://www.edf.org/sites/default/files/methane_studies_fact sheet.pdf

U.S. Energy Information Administration (EIA). (2014). “About U.S. Natural Gas Pipelines.” Washington, D.C.: EIA. Accessed

October 2014: http://www.eia.gov/pub/oil_gas/natural_gas/analysis_publications/ngpipeline/inde x.html. 
EIA. (2015). "U.S. Energy Information Administration: Independent Statistics and Analysis." Washington, D.C.: EIA. Accessed January 2015: http://www.eia.gov/.

U.S. Environmental Protection Agency (EPA). (2011). Inventory of U.S. GHG Emissions and Sinks: 1990-2009. EPA 430-R-11-005. Washington, D.C.: EPA. Accessed

October 2014: http://www.epa.gov/climatechange/Downloads/ghgemissions/US-GHGInventory-2011-Complete_Report.pdf.

EPA. (2013a). Oil and Natural Gas Sector: New Source Performance Standards and National Emission Standards for Hazardous Air Pollutants Reviews. Washington. D.C.: EPA. Accessed January 2015: http://www.epa.gov/airquality/oilandgas/pdfs/20120417finalrule.pdf.

EPA. (2013b). Global Mitigation of Non- $\mathrm{CO}_{2}$ Greenhouse Gases: 2010-2030. Washington, D.C.: EPA. Accessed

September 2014: http://www.epa.gov/climatechange/Downloads/EPAactivities/MAC_Report_20 13.pdf.

EPA. (2014a). Inventory of U.S. GHG Emissions and Sinks: 1990-2012. EPA 430-R-14-003.

Washington, D.C.: EPA. Accessed

October 2014: http://www.epa.gov/climatechange/Downloads/ghgemissions/US-GHGInventory-2014-Main-Text.pdf.

EPA. (2014b). 2011-2012-2013 GHGRP Industrial Profiles: Petroleum and Natural Gas Systems. Washington, D.C.: EPA. Accessed

September 2014: http://www.epa.gov/ghgreporting/documents/pdf/2014/documents/Subpart-W2013-Data-Summary.pdf.

EPA. (2014c). "Natural Gas STAR Program: Recommended Technologies and Practices." Washington, D.C.: EPA. Accessed

November 2014: http://www.epa.gov/gasstar/tools/recommended.html.

EPA. (2014d). Greenhouse Gas Reporting Rule: 2015 Revisions and Confidentiality Determinations for Petroleum and Natural Gas Systems. Washington, D.C.: EPA.

Accessed

January 2015: http://www.epa.gov/ghgreporting/documents/pdf/2014/documents/subpart w 2015 revisions.pdf.

EPA. (2014e). "Key Components of Natural Gas STAR.” Washington, D.C.: EPA. Accessed January 2015: http://www.epa.gov/gasstar/guidelines/keycomponents.html.

EPA. (2014f). "White Papers on Methane and VOC Emissions." Washington, D.C.: EPA. Accessed December 2014: http://www.epa.gov/airquality/oilandgas/whitepapers.html.

EPA. (2015a). DRAFT Inventory of U.S. GHG Emissions and Sinks: 1990-2013. EPA 430-R-13001. Washington, D.C.: EPA. Accessed March

2015: http://www.epa.gov/climatechange/Downloads/ghgemissions/US-GHG-Inventory-2013Main-Text.pdf. 
EPA. (2015b). Greenhouse Gas Reporting Program (GHGRP). Accessed December 2014: http:/www.epa.gov/ghgreporting/.

Federal Register. (2014). Part II Environmental Protection Agency. 40 CFR Part 98, Subpart A, Table A-1. Accessed December 2014: http://www.ecfr.gov/cgi-bin/textidx?tpl=/ecfrbrowse/Title40/40cfr98 main 02.tpl.

Harrison, M.; Shires, T.; Wessels, J.; Cowgill, R. (1996). Methane Emissions from the Natural Gas Industry Environmental Protection Agency, Washington, DC, EPA/600/SR-96/080.

Accessed January 2015: http://epa.gov/gasstar/tools/related.html.

Harvey, S.; Gowrishankar, V.; Singer, T. (2012). Leaking Profits: The U.S. Oil and Gas Industry Can Reduce Pollution, Conserve Resources, and Make Money by Preventing Methane Waste. New York, NY: National Resources Defense Council (NRDC). Accessed September 2014: http://www.nrdc.org/energy/files/Leaking-Profits-Report.pdf.

Heath, G.A.; O’Donoughue, P.; Arent, D.; Bazilian, M. (2014a). "Harmonization of initial estimates of shale gas life cycle greenhouse gas emissions for electric power generation." Proceedings of the National Academy of Sciences 111(31). Accessed

December 2014: http://www.pnas.org/content/111/31/E3167.full.pdf + html.

Heath, G.; Meldrum, J.; Fisher, N.; Arent, D.; Bazilian, M. (2014b). Life Cycle Greenhouse Gas Emissions from Barnett Shale Gas Used to Generate Electricity. Journal of Unconventional Oil and Gas Resources. Vol. 8, December 2014.

ICF International (ICF). (2014). Economic Analysis of Methane Emission Reduction Opportunities in the U.S. Onshore Oil and Natural Gas Industries. Fairfax, VA: ICF. Accessed September 2014: https://www.edf.org/sites/default/files/methane cost curve report.pdf.

Intergovernmental Panel on Climate Change (IPCC). (2006). 2006 Guidelines for National Greenhouse Gas Inventories. Geneva, Switzerland: IPCC. Accessed August 2014: http://www.ipcc-nggip.iges.or.jp/public/2006gl/.

IPCC. (2007). Fourth Assessment Report (AR4). Geneva, Switzerland: IPCC. Accessed August 2014: http://www.ipcc.ch/report/ar4/.

IPCC. (2013). Climate Change 2013: The Physical Science Basis. Geneva, Switzerland: IPCC. Accessed January 2015: https://www.ipcc.ch/report/ar5/wg1/.

Lamb, B.K.; Edburg, S.L.; Ferrara, T.W.; Howard, T.; Harrison, M.R.; Kolb, C.E.; TownsendSmall, A.; Dyck, W.; Possolo, A.; Whetstone, J.R. (2015). "Direct Measurements Show Decreasing Methane Emissions from Natural Gas Local Distribution Systems in the United States." Environmental Science and Technology 49(8), pp. 5161-5169.

Laurenzi, I.J.; Jersey, G.R. (2013). "Life Cycle Greenhouse Gas Emissions and Freshwater Consumption of Marcellus Shale Gas." Environmental Sciences and Technology 47(9); pp 48964903. 
Miller, C.A.; Hidy, G.; Hales, J.; Kolb, C.E.; Werner, A.S.; Haneke, B.; Parrish, D.; Frey, H.C.; Rojas-Bracho, L.; Deslauriers, M.; Pennell, B.; Mobley, J.D. (2006). "Air Emission Inventories in North America: A Critical Assessment.” Air \& Waste Management Association 56; pp. 1115-1129.

Mitchell, A.L.; Tkacik, D.S.; Roscioli, J.R.; Herndon, S.C.; Yacovitch, T.I.; Martinez, D.M.; Vaughn, T.L.; Williams, L.L.; Sullivan, M.R.; Floerchinger, C.; Omara, M.; Subramanian, R.; Zimmerle, D.; Marchese, A.J.; Robinson, A.L. (2015). "Measurements of methane emissions from natural gas gathering facilities and processing plants: measurement results." Environmental Science \& Technology 49; pp. 3219-3227. Accessed

February 2015: http://pubs.acs.org/doi/abs/10.1021/es5052809.

Oil and Gas Journal. (2014). “Oil and Gas Journal.” Tulsa, OK. Accessed January 2015: http://www.ogj.com/index.html.

Organization of Petroleum Exporting Countries. (2013). World Oil Outlook: Producing Oil Wells. 2011. World Oil Magazine. Accessed January 2015: http://www.opec.org/opec_web/static files_project/media/downloads/publications/ WOO 2013.pdf

Peischl, J.; Ryerson, T.B.; Aikin, K.C.; de Gouw, J.A.; Gilman, J.B.; Holloway, J.S.; Lerner, B.M.; Nadkarni, R.; Neuman, J.A.; Nowak, J.B.; Trainer, M.; Warneke, C.; Parrish, D.D. (2015). "Quantifying atmospheric methane emissions from the Haynesville, Fayetteville, and northeastern Marcellus shale gas production regions." Journal of Geophysical Research: Atmosphere Accepted. Accessed February 2015: http://onlinelibrary.wiley.com/doi/10.1002/2014JD022697/abstract.

Phillips, N.G.; Ackley, R.; Crosson, E.R.; Down, A.; Hutyra, L.R.; Brondfield, M.; Karr, J.D.; Zhao, K.; Jackson, R.B. (2013). "Mapping urban pipeline leaks: Methane leaks across Boston." Environmental Pollution 173(1-4). Accessed January 2015: http://www.ourenergypolicy.org/wpcontent/uploads/2013/10/ENVPOL vol173 pp 1 to 4 2013.pdf.

Skone, T. (2014). "Understanding the Life Cycle Environmental Footprint of the Natural Gas Value Chain.” Morgantown, WV: NETL. Accessed January 2015: http://www.netl.doe.gov/File\%20Library/Research/Energy\%20Analysis/Publicati ons/NG-LCA-DOE-NETL-SKONE-NARUC-MTG-09FEB2014.pdf.

Subramanian, R.; Williams, L.L.; Vaughn, T.L.; Zimmerle,D.; Roscioli, J.R.; Herndon, S.C.; Yacovitch, T.I.; Floerchinger, C.; Tkacik, D.S.; Mitchell, A.L.; Sullivan, M.R.; Dallmann, T.R. Robinson, A.L. (2015). "Methane Emissions from Natural Gas Compressor Stations in the Transmission and Storage Sector: Measurements and Comparisons with the EPA Greenhouse Gas Reporting Program Protocol.” Environmental Science \& Technology 49; pp. 3252-3261. Accessed February 2015: http://pubs.acs.org/doi/abs/10.1021/es5060258.

United Nations Framework Convention on Climate Change (UNFCCC). (1998). Kyoto Protocol to the United Nations Framework Convention on Climate Change, Kyoto, Japan. 
United Nations Framework Convention on Climate Change (UNFCCC). (2014). Revision of the UNFCCC reporting guidelines on annual inventories for Parties included in Annex I to the Convention.

Wennberg, P.O.; Mui, W.; Wunch, D.; Kort, E.A.; Blake, D.R.; Atlas, E.L.; Santoni, G.W.; Wofsy, S.C.; Diskin, G.S.; Jeong, S.; Fischer, M.L. (2012). "On the Sources of Methane to the Los Angeles Atmosphere." Environmental Science and Technology 46(17); 9282-9289. Accessed December 2014: http://pubs.acs.org/doi/abs/10.1021/es301138y.

White House. "Fact Sheet: Administration Takes Steps Forward on Climate Action Plan by Announcing Actions to Cut Methane Emissions.” (2015). Washington, D.C.: The White House, Office of the Press Secretary. Accessed January 2015: http://www.whitehouse.gov/the-pressoffice/2015/01/14/fact-sheet-administration-takes-steps-forward-climate-action-plan-anno-1.

Zimmerle, D.J.; Williams, L.L.; Vaughn, T.L.; Quinn, C.; Subramanian, R.; Duggan, R.P.; Willson, B.; Opsomer, J.D.; Marchese, A.J.; Martinez, D.M.; Robinson, A.L. (2015). "Methane Emissions from the Natural Gas Transmission and Storage System in the United States." Environmental Science and Technology 49 (15), 9374-9383. Accessed July 2015: http://pubs.acs.org/doi/abs/10.1021/acs.est.5b01669. 


\section{Measurement and Inventory Study References (as Displayed in Figures 6 and C-1)}

\section{Figure 6 - Top-down Measurement Studies}

1. Peischl, J.; Ryerson, T.B.; Aikin, K.C.; de Gouw, J.A.; Gilman, J.B.; Holloway, J.S.; Lerner, B.M.; Nadkarni, R.; Neuman, J.A.; Nowak, J.B.; Trainer, M.; Warneke, C.; Parrish, D.D. (2015). "Quantifying atmospheric methane emissions from the Haynesville, Fayetteville, and northeastern Marcellus shale gas production regions." Journal of Geographysical Research: Atmosphere Accepted. Accessed February 2015: http://onlinelibrary.wiley.com/doi/10.1002/2014JD022697/abstract.

2. Cambaliza, M.O.L.; Shepson, P.B.; Bogner, J.; Caulton, D.R.; Stirm, B.; Sweeney, C.; Montzka, S.A.; Gurney, K.R.; Spokas, K.; Salmon, O.E.; Lavoie, T.N.; Hendricks, A.; Mays, K.; Turnbull, J.; Miller, B.R.; Lauvaux, T.; Davis, K.; Karion, A.; Moser, B.; Miller, C.; Obermeyer, C.; Whetstone, J.; Prasad, K.; Miles, N.; Richardson, S. (2015). "Quantification and source apportionment of the methane emission flux from the city of Indianapolis." Elementa: Science of the Anthropocene 3(000037), 18 pp. Accessed February

2015: http://elementascience.org/article/info:doi/10.12952/journal.elementa.000037.

3. Brantley, H.L.; Thoma, E.D.; Squier, W.C.; Guven, B.B.; Lyon, D. (2014). “Assessment of methane emissions from oil and gas production pads using mobile measurements." Environmental Science \& Technology 48, pp. 14508-14515. Accessed February 2015: http://pubs.acs.org/doi/full/10.1021/es503070q.

4. Schneising, O.; Burrows, J.P.; Dickerson, R.R.; Buchwitz, M.; Reuter, M.; Bovensmann, H. (2014). "Remote sensing of fugitivemethane emissions from oil and gas production in North American tight geologic formations." Future 2, pp. 548-558. Accessed February 2015: http://onlinelibrary.wiley.com/doi/10.1002/2014EF000265/abstract.

5. Caulton, D.R.; Shepson, P.B.; Cambaliza, M.; McCabe, D.; Baum, E.; Stirm, B.H. (2014). "Methane destruction efficiency of natural gas flares associated with shale formation wells." Environmental Science \& Technology 48, pp. 9548-9554. Accessed February 2015: http://pubs.acs.org/doi/abs/10.1021/es500511w.

6. Caulton, D.R.; Shepson, P.B.; Santoroc, R.L.; Sparks, J.; Howarth, J.; Ingraffea, A.; Cambaliza, M.; Sweeney, C.; Karion, A.; Davis, K.; Stirm, B.; Montzka, S.; Miller, B. (2014b). "Toward a better understanding and quantification of methane emissions from shale gas development." Proceedings of the National Academy of Sciences 111(17); pp. 6237-6242. Accessed December 2014: http://www.pnas.org/content/111/17/6237.abstract.

7. Pétron, G.; Karion, A.; Sweeney, C.; Miller, B.; Montzka, S.; Frost, G.; Trainer, M.; Tans, P.; Andrews, A.; Kofler, J.; Helmig, D.; Guenther, D.; Dlugokencky, E.; Lang, P.; Newberger, T.; Wolter, S.; Hall, B.; Novelli, P.; Brewer, A.; Conley, S.; Hardesty, M.; Banta, R.; White, A.; Noone, D.; Wolfe, D.; Schnell, R. (2014). "A new look at methane and non-methane hydrocarbon emissions from oil and natural gas operations in the Colorado Denver-Julesburg Basin." Journal of Geophysical Research Atmospheres 119; pp. 6836-6852. Accessed December 2014: http://onlinelibrary.wiley.com/doi/10.1002/2013JD021272/abstract. 
8. Miller, S.; Wofsy, S.; Michalak, A.; Kort, E.; Andrews, A.; Biraud, S.; Dlugokencky, E.; Eluszkiewicz, J.; Fischer, M.; Janssens-Maenhout, G.; Miller, B.; Miller, J.; Montzka, S.; Nehrkorn, T.; Sweeney, C. (2013). "Anthropogenic emissions of methane in the United States." Proceedings of the National. Academy of Sciences 110; pp. 20018-20022. Accessed December 2015: http://www.pnas.org/content/110/50/20018.abstract.

9. Karion, A.; Sweeney, C.; Pétron, G.; Frost, G.; Hardesty, R.; Kofler, J.; Miller, B.; Newberger, T.; Wolter, S.; Banta, R.; Brewer, A.; Dlugokencky, E.; Lang, P.; Montzka, S.; Schnell, R.; Tans, P.; Trainer, M.; Zamora, R.; Conley, S. (2013). "Methane emissions estimate from airborne measurements over a western United States natural gas field." Geophysical Research Letters 40; pp. 4393-4397. Accessed December

2014: http://onlinelibrary.wiley.com/doi/10.1002/grl.50811/abstract.

10. Pétron, G.; Frost, G.; Miller, B.; Hirsch, A.; Montzka, S.; Karion, A.; Trainer, M.; Sweeney, C.; Andrews, A.; Miller, L.; Kofler, J.; Bar-Ilan, A.; Dlugokencky, E.; Patrick, L.; Moore, C.; Ryerson, T.; Siso, C.; Kolodzey, W.; Lang, P.; Conway, T.; Novelli, P.; Masarie, K.; Hall, B.; Guenther, D.; Kitzis, D.; Miller, J.; Welsh, D.; Wolfe, D.; Neff, W.; Tans, P. (2012).

"Hydrocarbon emissions characterization in the Colorado Front Range: A pilot study." Journal of Geophysical Research Atmospheres 117, (D4). Accessed December

2014: http://onlinelibrary.wiley.com/doi/10.1029/2011JD016360/abstract.

11. Kort, E.; Eluszkiewicz, J.; Stephens, S.; Miller, J.; Gerbig, C.; Nehrkorn, T.; Daube, B.; Kaplan, J.; Houweling, S.; Wofsy, S. (2008). "Emissions of CH 4 and N 2 O over the United States and Canada based on a receptor-oriented modeling framework and COBRA-NA atmospheric observations." Geophysical Research Letters 35; L18808. Accessed December 2014: http://onlinelibrary.wiley.com/doi/10.1029/2008GL034031/abstract.

12. Katzenstein, A.; Doezema, L.; Simpson, I.; Blake, D.; Rowland, F. (2003). "Extensive regional atmospheric hydrocarbon pollution in the southwestern United States." Proceedings of the National Academy of Sciences 100; pp. 11975-11979. Accessed December 2014: http://www.pnas.org/content/100/21/11975.full.

13. Hsu, Y-K.; VanCuren, T.; Park, S.; Jakober, C.; Herner, J.; FitzGibbon, M.; Blake, D.; Parrish, D. (2010). "Methane emissions inventory verification in southern California." Atmospheric Environment 44; pp. 1-7. Accessed December 2014: http://www.lgrinc.com/publications/Methane\%20emissions\%20inventory\%20verification $\% 20 \mathrm{in} \% 20$ southern $\% 20$ California.pdf.

14. Wunch, D.; Wennberg, P.; Toon, G.; Keppel-Aleks, G.; Yavin, Y. (2009). "Emissions of greenhouse gases from a North American megacity." Geophysical Research Letters 36(15). Accessed December 2014: http://onlinelibrary.wiley.com/doi/10.1029/2009GL039825/abstract.

15. Peischl, J.; Ryerson, T.; Brioude1, J.; Aikin, K.; Andrews, A.; Atlas, E.; Blake, D.; Daube, B.; de Gouw, J.; Dlugokencky, E.; Frost, G.; Gentner, D.; Gilman, J.; Goldstein, A.; Harley, R.; Holloway, J.; Kofler, J.; Kuster, W.; Lang, P.; Novelli, P.; Santoni, G.; Trainer, M.; Wofsy, S.; Parrish, D. (2013). "Quantifying sources of methane using light alkanes in the Los Angeles 
basin, California." Journal of Geophysical Research Atmospheres 118; 4974. Accessed December 2014: http://onlinelibrary.wiley.com/doi/10.1002/jgrd.50413/abstract.

16. Wennberg, P.; Mui, W.; Wunch, D.; Kort, E.; Blake, D.; Atlas, E.; Santoni, G.; Wofsy, S.; Diskin, G.; Jeong, S.; Fischer, M. (2012). "On the sources of methane to the Los Angeles atmosphere.” Environmental Science and Technology 46; pp. 9282-9289. Accessed December 2014: http://pubs.acs.org/doi/abs/10.1021/es301138y.

17. Xiao, Y.; Logan, J.; Jacob, D.; Hudman, R.; Yantosca, R.; Blake, D. (2008). "Global budget of ethane and regional constraints on U.S. sources." Journal of Geophysical Research

Atmospheres 113. Accessed December

2014: http://onlinelibrary.wiley.com/doi/10.1029/2007JD009415/abstract.

18. Wang, J.; Logan, J.; McElroy, M.; Duncan, B.; Megretskaia, I.; Yantosca, R. (2004). “A 3-D model analysis of the slowdown and interannual variability in the methane growth rate from 1988 to 1997." Global Biogeochem. Cycles 18 (361). Accessed December 2014: http://onlinelibrary.wiley.com/doi/10.1029/2003GB002180/abstract.

\section{Figure 6 - Bottom-up Measurement Studies}

19. Subramanian, R.; Williams, L.L.; Vaughn, T.L.; Zimmerle,D.; Roscioli, J.R.; Herndon, S.C.; Yacovitch, T.I.; Floerchinger, C.; Tkacik, D.S.; Mitchell, A.L.; Sullivan, M.R.; Dallmann, T.R. Robinson, A.L. (2015). "Methane Emissions from Natural Gas Compressor Stations in the Transmission and Storage Sector: Measurements and Comparisons with the EPA Greenhouse Gas Reporting Program Protocol." Environmental Science \& Technology 49; pp. 3252-3261. Accessed February 2015: http://pubs.acs.org/doi/abs/10.1021/es5060258.

20. Mitchell, A.L.; Tkacik, D.S.; Roscioli, J.R.; Herndon, S.C.; Yacovitch, T.I.; Martinez, D.M.; Vaughn, T.L.; Williams, L.L.; Sullivan, M.R.; Floerchinger, C.; Omara, M.; Subramanian, R.; Zimmerle, D.; Marchese, A.J.; Robinson, A.L. (2015). "Measurements of methane emissions from natural gas gathering facilities and processing plants: measurement results." Environmental Science \& Technology 49, pp. 3219-3227. Accessed February 2015: http://pubs.acs.org/doi/abs/10.1021/es5052809.

2. Cambaliza, M.O.L.; Shepson, P.B.; Bogner, J.; Caulton, D.R.; Stirm, B.; Sweeney, C.; Montzka, S.A.; Gurney, K.R.; Spokas, K.; Salmon, O.E.; Lavoie, T.N.; Hendricks, A.; Mays, K.; Turnbull, J.; Miller, B.R.; Lauvaux, T.; Davis, K.; Karion, A.; Moser, B.; Miller, C.; Obermeyer, C.; Whetstone, J.; Prasad, K.; Miles, N.; Richardson, S. (2015). "Quantification and source apportionment of the methane emission flux from the city of Indianapolis." Elementa: Science of the Anthropocene 3(000037), pp. 1-18. Accessed February

2015: http://elementascience.org/article/info:doi/10.12952/journal.elementa.000037.

21. McKain, K.; Down, A.; Raciti, S.M.; Budney, J.; Hutyra, L.R.; Floerchinger, C.; Herndon, S.C.; Nehrkom, T.; Zahniser, M.S.; Jackson, R.B.; Phillips, N.; Wofsy, S.C. (2014). "Methane emissions from natural gas infrastructure and use in the urban region of Boston, Massachusetts." Proceedings of the National Academy of Sciences 112(7), pp. 1941-1946. Accessed February 2015: http://www.pnas.org/content/112/7/1941. 
22. Canadian Association of Petroleum Producers (CAPP). (2014). Update of Fugitive Equipment Leak Emission Factors. Calgary, Alberta: CAPP. Accessed November 2014: http://www.capp.ca/getdoc.aspx?DocId=238773\&DT=NTV.

23. Oklahoma Independent Petroleum Association (OIPA). (2014). Pneumatic controller Emissions from a sample of 172 production facilities. Oklahoma City, OK: OIPA. Accessed February 2015: http://www.oipa.com/custom/shownewsmulti.php?action=detail\&id=531.

24. Allen, D.; Sullivan, D.; Zavala-Araiza, D.; Pacsi, A.P.; Harrison, M.; Keen, K.; Fraser, M.P.; Hill, D.; Lamb, B.K.; Sawyer, R.F.; Seinfeld, J.H. (2015a). "Methane Emissions from Process Equipment at Natural Gas Production Sites in the United States: Liquid Unloadings." Environmental Science \& Technology 49(1); pp. 641-648. Accessed January 2015: http://pubs.acs.org/doi/abs/10.1021/es504016r.

25. Allen, D. Pacsi, A.P.; Sullivan, D.; Zavala-Araiza, D.; Harrison, M.; Keen, K.; Fraser, M.P.; Hill, D.; Sawyer, R.F.; Seinfeld, J.H. (2015b). "Methane Emissions from Process Equipment at Natural Gas Production Sites in the United States: Pneumatic Controllers." Environmental Science \& Technology 49(1); pp. 633-640. Accessed January 2015: http://pubs.acs.org/doi/abs/10.1021/es5040156.

26. Kang, M.; Kanno, C.M.; Reid, M.C.; Zhang, X.; Mauzerall, D.L.; Celia, M.A.; Chen, Y.; Onstott, T.C. "Direct measurements of methane emissions from abandoned oil and gas wells in Pennsylvania." Proceedings of the National Academy of Sciences 111(51), pp. 18173-18177. Accessed February 2015: http://www.pnas.org/content/111/51/18173.abstract.

27. Allen, D.; Torres,V.M.; Thomas, J.; Sullivan, D.W.; Harrison, M.; Hendler, A.; Herndon, S.C.; Kolb, C.E.; Fraser, M.P.; Hill, D.; Lamb, B.K.; Miskimins, J.; Sawyer, R.F.; Seinfeld, J.H. (2013). "Measurements of Methane Emissions at Natural Gas Production Sites in the United States." Proceedings of the National Academy of Sciences 110(44). Accessed December 2014: http://www.pnas.org/content/110/44/17768.abstract.

28. Alvarez, R.; Pacala, S.; Winebrake, J.; Chameides, W.; Hamburg, S. (2012). "Greater focus needed on methane leakage from natural gas infrastructure." Proceedings of the National Academy of Sciences 109(17); pp. 6435-6440. Accessed December 2014: http://www.pnas.org/content/109/17/6435.full.pdf+html.

29. Harrison, M.; Galloway, K.; Hendler, A.; Shires, T.; Allen, D.; Foss, M.; Thomas, J.; Spinhirne, J. (2011). Natural Gas Industry Methane Emissions Factor Improvement Study. EPA Cooperative Agreement No. XA-83376101. Washington, D.C.: EPA. Accessed November 2014: http://www.utexas.edu/research/ceer/GHG/files/FReports/XA_83376101_Final_Report.pdf.

30. Gas Technology Institute (GRI). (2009). Field Measurement Program to Improve Uncertainties for Key Greenhouse Gas Emissions Factors for Distribution Sources. OTD-100002. Des Plaines, IL: Gas Technology Institute. Accessed December 2014 : http://www.otdco.org/reports/Documents/77b OTD-10-0002 GHG Emission Factors FinalReport v2.pdf. 
31. Clearstone Engineering. (2002). Identification and Evaluation of Opportunities to Reduce methane Losses at Four Gas Processing Plants. USEPA Grant No. 827754-01-0. Des Plaines, IL: Gas Technology Institute. Accessed December

2014: http://epa.gov/gasstar/documents/four_plants.pdf.

32. Johnson, D.; Covington, A.; Clark, N. (2014). "Environmental and Economic Assessment of Leak and Loss Audits at Natural Gas Compressor and Storage Facilities." Energy Technology 2, pp. 1027-1032. Accessed February

2015: http://onlinelibrary.wiley.com/doi/10.1002/ente.201402086/abstract

33. National Gas Machinery Laboratory, Clearstone Engineering, and Innovative Environmental Solutions. (2006). Cost-Effective Directed Inspection and Maintenance Control Opportunities at Five Gas Processing Plants and Upstream Gathering Compressor Stations and Well Sites. U.S. EPA Grant No. XA-83046001-1. Washington, D.C.: EPA. Accessed January 2015: http://www.epa.gov/gasstar/documents/clearstone_II_03 2006.pdf.

34. Chambers, A. (2004). Optical Measurement Technology for Fugitive Emissions from Upstream Oil and Gas Facilities. Edmonton, Alberta: Alberta Research Council. Accessed December 2014: http://www.epa.gov/gasstar/documents/clearstone_II 03_2006.pdf.

35. Trefiak, T. (2006). Pilot study: Optical leak detection and measurement. Houston, TX: ConocoPhillips. Accessed December 2014: http://www.flir.com/uploadedFiles/Thermography_USA/Industries/OGI/7_Pilot_Study.pdf.

36. Shorter, J.; McManus, J.; Kolb, C.; Allwine, E.; Lamb, B.; Mosher, B.; Harriss, R.; Howard, T.; Lott, R. (1997). "Collection of Leakage Statistics in the Natural Gas System by Tracer Methods." Environmental Science and Technology 31; pp. 2012- 2019. Accessed December 2014: http://pubs.acs.org/doi/pdf/10.1021/es9608095.

37. Harrison, M.; Shires, T.; Wessels, J.; Cowgill, R. (1997). Methane Emissions from the Natural Gas Industry. EPA/600/SR-96/080. Washington, D.C.: EPA. Accessed January 2015: http://epa.gov/gasstar/tools/related.html.

38. Carbon Limits. (2014). Quantifying Cost-effectiveness of Systematic Leak Detection and Repair Programs Using Infrared Cameras. Report CL-13-27. Oslo, Norway: Carbon Limits. Accessed December 2014: http://www.catf.us/resources/publications/files/Carbon_Limits_LDAR.pdf.

39. Rich, A.L Grover, J.P.; Sattler, M.L. (2014). "An exploratory study of air emissions associated with shale gas development and production in the Barnett Shale." Journal of the Air \& Waste Management Association 64(1), pp. 61-72. Accessed February

2015: http://www.tandfonline.com/doi/abs/10.1080/10962247.2013.832713\#.VP4vSXJ0y70

40. Jackson, R.; Down, A.; Phillips, N.; Ackley, R.; Cook, C.; Plata, D.; Zhao, K. (2014). "Natural Gas Pipeline Leaks Across Washington, D.C." Environmental Science and Technology 48 (3); pp. 2051-2058. Accessed December 2014: http://pubs.acs.org/doi/abs/10.1021/es404474x. 
41. Phillips, N.G.; Ackley, R.; Crosson, E.R.; Down, A.; Hutyra, L.R.; Brondfield, M.; Karr, J.D.; Zhao, K.; Jackson, R.B. (2013). "Mapping urban pipeline leaks: Methane leaks across Boston." Environmental Pollution 173(1-4). Accessed January

2015: http://www.ourenergypolicy.org/wpcontent/uploads/2013/10/ENVPOL_vol173 pp_1_to_4_2013.pdf.

Figure B-1 - Inventory Studies

1. EPA. (2014). Inventory of U.S. GHG Emissions and Sinks: 1990-2012. EPA 430-R-14-003. Washington, D.C.: EPA. Accessed October

2014: http://www.epa.gov/climatechange/Downloads/ghgemissions/US-GHG-Inventory-2014Main-Text.pdf.

2. Western Regional Air Partnership (WRAP). (2005a.) Oil and Gas Emission Inventories for the Western States: Final Report. Environ International Corp. for Western Governors' Association. Accessed October

2014: http://www.wrapair.org/forums/ssjf/documents/eictts/OilGas/WRAP_Oil\&Gas_Final_Rep ort.122805.pdf.

WRAP. (2005b). An Emission Inventory of Non-point Oil and Gas Emissions Sources in the Western Region. Environ International Corp. Accessed October 2014: http://www.epa.gov/ttnchie1/conference/ei15/session12/russell.pdf.

3. Jeong, S.; Millstein, D.; Fischer, M. (2014). "Spatially Explicit Methane Emissions from Petroleum Production and the Natural Gas System in California." Environmental Science and Technology 48 (10); pp. 5982-5990. Accessed November

2014: http://pubs.acs.org/doi/abs/10.1021/es4046692.

4. California Air Resources Board (CARB). (2011). 2007 Oil and Gas Industry Survey Results: Final Report. Accessed November 2014: http://www.arb.ca.gov/cc/oil-gas/finalreport.pdf.

5. WRAP. (2013a). Development of Baseline 2009 Emissions from Oil and Gas Activity in the Williston Basin: Final Report. Environ International Corp. for Western Energy Alliance. Accessed October 2014: http://www.wrapair2.org/pdf/2009 Baseline_Emiss_Williston_Basin_062513.pdf.

WRAP. (2013b). Development of 2015 Oil and Gas Emissions Projections for the Williston Basin: Final Report. Environ International Corp. for Western Energy Alliance. Accessed October 2014: http://www.wrapair2.org/pdf/2015_Proj_Emiss_Williston_Basin_072513.pdf.

6. WRAP. (2012d). Development of 2009 Oil and Gas Emissions Updates for Wyoming Basins: Final Report. Environ International Corp. for Western Energy Alliance. Accessed November 2014: http://www.wrapair2.org/pdf/2009_Updates_Wyoming_Basins_112912.pdf.

7. WRAP. (2011). Development of Baseline 2006 Emissions from Oil and Gas Activity in the Powder River Basin: Final Report. Environ International Corp. for Western Energy Alliance and Buys \& Associates, Inc. Accessed December 2014: http://www.wrapair2.org/pdf/2011$06 \% 2706 \% 20$ Baseline $\% 20$ Emissions; $\% 20$ Powder $\% 20$ River $\% 20$ Basin $\% 20 \% 2806-10 \% 29$.pdf. 
WRAP. (2012c). Development of 2015 Oil and Gas Emissions Projections for the Powder River Basin: Draft Final Report. Environ International Corp. for Western Energy Alliance and Buys \& Associates, Inc. Accessed December

2014: http://www.wrapair2.org/pdf/2015_Proj_Emiss_Powder_River_Basin_112712.pdf.

8. WRAP. (2010a). Development of Baseline 2006 Emissions from Oil and Gas Activity in the Wind River Basin: Final Report. Environ International Corp. for Western Energy Alliance and Buys \& Associates, Inc. Accessed October

2014: http://www.wrapair2.org/pdf/2006_Baseline_Emiss_SWWY Basin 120712.pdf.

WRAP. (2010b). Development of 2012 Oil and Gas Emissions Projections for the Wind River Basin: Final Report. Environ International Corp. for Buys \& Associates, Inc. and Independent Petroleum Association of Mountain States (IPAMS). Accessed October

2014: http://www.wrapair.org/forums/ogwg/documents/2010-

$07 \% 2712 \% 20$ Projections; $\% 20 \mathrm{WindRiver} \% 20 \mathrm{Basin} \% 20 \mathrm{Technical} \% 20 \mathrm{Memo} \% 20 \% 2807$ $14 \% 29 . p d f$.

9. Bureau of Indian Affairs (BIA). (2004). Emissions Inventory For the Wind River Natural Gas Field Development Project. Buys \& Associates for BIA. Accessed December

2014: http://teeic.indianaffairs.gov/documents/docs/library/WindRiverDraftV3Emission.pdf.

10. WRAP. (2012a). Development of Baseline 2006 Emissions from Oil and Gas Activity in the Southwest Wyoming (Greater Green River) Basin: Final Report. Environ International Corp. Accessed November 2014: http://www.wrapair2.org/pdf/2006_Baseline_Emiss_SWWY_Basin_120712.pdf.

WRAP. (2012b). Development of 2015 Oil and Gas Emissions Projections for the Southwest Wyoming Basin: Final Report. Environ International Corp. Accessed November 2014: http://www.wrapair2.org/pdf/2015 Proj Emiss SWWY Basin 112712.pdf.

11. Reid, S.; Pollard, E.; Reed, J.; Taylor, C.; Bohlmann, B. (2012). "Preparation of Oil and Gas Emissions Inventories for Use in Photochemical Modeling." Presented at the 11th Annual CMAS Conference, Chapel Hill, NC, October 15-17. Accessed December 2014: https://www.cmascenter.org/conference/2012/abstracts/reid preparation_oil_2012.pdf.

12. Utah Bureau of Land Management (UT BLM). (2013). Utah State BLM Emissions Inventory Technical Support Document. AECOM for BLM. Accessed January 2015: http://www.blm.gov/pgdata/etc/medialib/blm/ut/natural_resources/airQuality.Par.34346.Fi le.dat/UTSO EmissionsTSD121913.pdf.

13. WRAP. (2009e). Development of Baseline 2006 Emissions from Oil and Gas Activity in the Uinta Basin: Final Report. Environ International Corp. Accessed November 2014: http://www.wrapair.org/forums/ogwg/documents/20090306 Baseline Emissions Uinta Basin Technical Memo 03-25.pdf.

WRAP. (2009f). Development of 2012 Oil and Gas Emissions Projections for the Uinta Basin: Final Report. Environ International Corp. Accessed November 
2014: http://www.wrapair.org/forums/ogwg/documents/2009-

03_12_Projection_Emissions_Uinta_Basin_Technical_Memo_03-25.pdf.

14. WRAP. (2009a). Development of Baseline 2006 Emissions from Oil and Gas Activity in the Piceance Basin: Final Report. Environ International Corp. Accessed November 2014: http://www.wrapair.org/forums/ogwg/documents/2009-

01_06_Baseline_Emissions_Piceance_Basin_Technical_Memo_01-20.pdf.

WRAP. (2009b). Development of 2012 Oil and Gas Emissions Projections for the Piceance Basin: Final Report. Accessed January

2015: http://www.wrapair.org/forums/ogwg/documents/2009-

01_12_Projection_Emissions_Piceance_Basin_Technical_Memo_01-21.pdf.

15. WRAP. (2008a). Development of Baseline 2006 Emissions from Oil and Gas Activity in the Denver-Julesburg Basin. Accessed January

2015: http://www.wrapair.org/forums/ogwg/documents/2008-

04_06 Baseline_Emissions_DJ_Basin_Technical_Memo_(04-30).pdf.

WRAP. (2008b). Development of 2010 Oil and Gas Emissions Projections for the DenverJulesburg Basin. Environ International Corp. Accessed December

2014: http://apcd.state.co.us/documents/deno308/2008-

04_2710_Projection_Emissions_DJ_Basin_Technical_Memo\%2804-30\%29.pdf.

16. WRAP. (2009g). Development of Baseline 2006 and Midterm 2012 Emissions from Oil and Gas Activity in the North San Juan Basin: Final Report. Environ International Corp. Accessed December 2014: http://www.wrapair.org/forums/ogwg/documents/NSanJuanBasin/200909 06 Baseline and 12_Midterm_Emissions_N_San_Juan_Basin_Technical_Memo 0901.pdf.

17. WRAP. (2009c). Development of Baseline 2006 Emissions from Oil and Gas Activity in the South San Juan Basin: Final Report. Environ International Corp. Accessed December 2014: http://www.wrapair.org/forums/ogwg/documents/SSanJuanBasin/200911y_06_Baseline_S_San_JuanBasin_Technical_Memo_11-25R.pdf.

WRAP. (2009d). Development of 2012 Oil and Gas Emissions Projections for the South San Juan Basin: Final Report. Environ International Corp. Accessed December 2014: http://www.wrapair.org/forums/ogwg/documents/SSanJuanBasin/200912 12\%20Projections_S_SanJuan_Basin_Technical_Memo_12-08R.pdf.

18. New Mexico Environment Department. 2006. Ozone Precursor Emission Inventory for San Juan and Rio Arriba Counties, New Mexico. Prepared by Environ International Corp. and Eastern Research Group. Accessed January

2015: http://www.wrapair.org/forums/ogwg/documents/NM_Area_Emissions_report.pdf.

19. Texas Commission for Environmental Quality (TCEQ). (2007). Emissions from Oil and Gas Production Facilities: Final Report. 582-7-84003. Prepared by Eastern Research Group. Accessed December 
2014: http://www.tceq.state.tx.us/assets/public/implementation/air/am/contracts/reports/ei/58207 84003FY0701-20090831-ergi-ei_from_old_gas_facilities.pdf.

20. TCEQ. (2009a). Drilling Rig Emission Inventory for the State of Texas: Final Report. Prepared by Eastern Research Group. Accessed November 2014: http://www.tceq.state.tx.us/assets/public/implementation/air/am/contracts/reports/ei/58207 83985FY0901-20090715-ergi-Drilling_Rig_EI.pdf.

21. TCEQ. (2011). Appendix 8: Development of Texas Statewide Drilling Rigs Emission Inventories for the Years 1990, 1993, 1996, and 1999 Through 2040: Final Report. 582-1199776. Prepared by Eastern Research Group. Accessed December 2014: http://www.tceq.texas.gov/assets/public/implementation/air/sip/dfw/dfw_rfp_sip_2015/DF WRFP SIP Appendix 8.pdf.

22. Zavala-Araiza, D.; Sullivan, D.; Allen, D. (2014). "Atmospheric Hydrocarbon Emissions and Concentrations in the Barnett Shale Natural Gas Production Region." Environmental Science and Technology 48 (9); pp. 5314-5321. Accessed December 2014: http://pubs.acs.org/doi/abs/10.1021/es405770h.

23. Heath, G.; Meldrum, J.; Fisher, N. (2012) "Chapter 1: Life Cycle Greenhouse Gas Emissions from Barnett Shale Gas Used to Generate Electricity." In: Joint Institute for Strategic Energy Analysis (JISEA). Natural Gas and the Transformation of the U.S. Energy Sector: Electricity. Logan, J.; Heath, G.; Macknick, J.; Paranhos, E.; Boyd, W.; Carlson, K. NREL/TP-6A50-55538. Golden, CO: National Renewable Energy Laboratory. Accessed October 2014: http://www.nrel.gov/docs/fy13osti/55538.pdf.

24. EDF. (2009). Emissions from Natural Gas Production in the Barnett Shale Area and Opportunities for Cost-Effective Improvements. Accessed December 2014: http://www.edf.org/sites/default/files/9235 Barnett Shale Report.pdf.

25. TCEQ. (2009c). 2009 Barnett Shale Phase I Inventory County Count of Sources by Profile. Accessed January 2015: http://www.tceq.state.tx.us/airquality/point-source-ei/psei.html\#barnett

26. TCEQ. (2014). Oil and Gas Emission Inventory, Eagle Ford Shale. Prepared by the Alamo Area Council of Governments. Accessed November 2014: http://www.aacog.com/documentcenter/view/19069.

27. Arkansas Department of Environmental Quality (ADEQ). ( 2011a). Emissions Inventory \& Ambient Air Monitoring of Natural Gas Production in the Fayetteville Shale Region. Accessed January 2015: http://www.adeq.state.ar.us/air/pdfs/fayetteville_shale_air_quality_report_tagged.pdf.

ADEQ. (2011b). Emissions Inventory \& Ambient Air Monitoring of Natural Gas Production in the Fayetteville Shale Region. Conference Paper. Accessed January

2015: http://www.epa.gov/ttnchie1/conference/ei20/session6/dlyon.pdf. 
28. TCEQ. (2009b). Development of an Emission Inventory for Natural Gas Exploration and Production in the Haynesville Shale. Draft Report. Accessed January 2015: http://www.netac.org/UserFiles/File/NETAC/9 29 09/Enclosure_2b.pdf.

29. U.S. Department of the Interior (DOI). (2004). Data Quality Control and Emissions Inventories of OCS Oil and Gas Production Activities in the Breton Area of the Gulf of Mexico: Final Report. Prepared by Eastern Research Group. Accessed December 2014: www.data.boem.gov/PI/PDFImages/ESPIS/2/3008.pdf.

30. Pennsylvania Department of Environmental Protection. (2012). 2012 Natural Gas Emissions Inventory by Source Type. Accessed January 2015: http://www.portal.state.pa.us/portal/server.pt/community/Emission\%20Inventory/21810/M arcellus\%20Inventory/1829967.

31. Rose, Adam, Brent Yarnal, Robert Neff, Howard Greenberg, Mohammed Kharbach, and Cheng-Hau Peng. (2003). Greenhouse Gas Emissions Inventory for Pennsylvania Phase I Report. Harrisburg, PA: Pennsylvania Department of Environmental Protection. Accessed January

2015: https://www.google.com/url? sa=t\&rct=j\&q=\&esrc=s\&source=web\&cd=1\&ved=0CB8QFj AAahUKEwir7qOfqabHAhUEdT4KHQpDBOc\&url=http $\% 3 \mathrm{~A} \% 2 \mathrm{~F} \% 2 \mathrm{Fwww}$.dli.state.pa.us $\% 2$

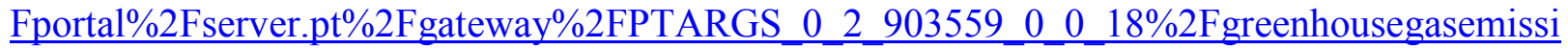
onsinventory.pdf\&ei $=$ vrDMVauXJ4TqQGKhpG4Dg\&usg=AFQjCNGiADJ2nK4D0NCoOKIYc66Is mqvg\&bvm=bv.99804247,d.cW w\&cad=rja. 


\section{Appendix A. U.S. GHGI Data}

Figures A-1 - A-3 show U.S. GHGI estimates of methane emissions from production, gathering, and boosting; processing; and transmission and storage, respectively (EPA 2014a). These figures show fugitives and venting or combustion exhaust emissions for each emission source category. Many emission categories shown are aggregations of the nearly 110 source categories in the U.S. GHGI. As much as feasible, we based our labeling of these emission source categories on the terminology and categorization of emissions used in the U.S. GHGI. For clarity and consistency across figures we have made some modifications to the U.S. GHGI terminology.

Tables A-1 - A-4 show how methane emission estimates from the U.S. GHGI are processed for use in Figures A-1 - A-3 and Figure 4. Data processing involved transformation of units of measure, application of emission reductions from policies and voluntary industry actions (EPA 2014a), and aggregation of emission source categories to simplify the figures. 
Table A-1. U.S. GHGI Estimates of Natural Gas Methane $\left(\mathrm{CH}_{4}\right)$ Emissions in 2012 from the Production and Gathering and Boosting Segment of the Natural Gas Supply Chain. Light orange cells indicate where we have summed emissions reductions from voluntary and required emission reductions reported in U.S. GHGI. Dark orange cells show emission reduction we calculated from the "Other Production" emission reductions reported in the U.S. GHGI. ${ }^{33}$ Green cells indicate that the U.S. GHGI directly reported net emissions for this category.

\begin{tabular}{|c|c|c|c|c|c|c|c|}
\hline \multirow[t]{2}{*}{$\begin{array}{l}\text { Emission } \\
\text { Type }\end{array}$} & \multirow[t]{2}{*}{ Emission Source Category } & \multicolumn{2}{|c|}{$\begin{array}{l}\text { Potential } \\
\text { Emissions }\end{array}$} & \multirow{2}{*}{$\begin{array}{c}\begin{array}{c}\text { Emissions } \\
\text { Reductions }\end{array} \\
\text { MMt } \mathrm{CO}_{2} \mathrm{e} / \mathrm{yr} \\
\end{array}$} & \multirow{2}{*}{$\begin{array}{l}\text { Net Emissions } \\
\mathrm{MM} \mathrm{CO}_{2} \mathrm{e} / \mathrm{yr}\end{array}$} & \multirow[t]{2}{*}{$\begin{array}{l}\text { Figure A-1 Emission } \\
\text { Source Categories }\end{array}$} & \multirow{2}{*}{$\begin{array}{l}\text { Aggregated Net } \\
\text { Emissions } \\
\text { MMt CO } \mathrm{CO}_{2} \mathrm{e} / \mathrm{yr} \\
\end{array}$} \\
\hline & & $\mathrm{Gg} \mathrm{CH}_{4} / \mathrm{yr}$ & MMt CO $\mathrm{CO}_{2} \mathrm{yr}$ & & & & \\
\hline \multirow{9}{*}{ Fugitives } & Non-Associated Gas Wells (less wells with hydraulic fracturing) & 18 & 0.46 & -0.25 & 0.21 & \multirow{6}{*}{ Onshore wells \& Sep. } & \multirow{6}{*}{3.9} \\
\hline & Gas Wells with Hydraulic Fracturing & 35 & 0.89 & -0.47 & 0.42 & & \\
\hline & Field Separation Equipment - Heaters & 33 & 0.83 & -0.44 & 0.39 & & \\
\hline & Field Separation Equipment - Separators & 107 & 2.7 & -1.4 & 1.3 & & \\
\hline & Field Separation Equipment - Dehydrators & 33 & 0.82 & -0.43 & 0.39 & & \\
\hline & Field Separation Equipment - Meters/Piping & 106 & 2.7 & -1.4 & 1.3 & & \\
\hline & Small Reciprocating Compressors & 71 & 1.8 & -0.94 & 0.83 & \multirow{2}{*}{ Recip. compres. stations } & \multirow{2}{*}{1.0} \\
\hline & Large Reciprocating Stations & 1 & 0.03 & -0.01 & 0.01 & & \\
\hline & Pipeline Leaks & 176 & 4.4 & 0.00 & 4.4 & Pipeline leaks & 4.4 \\
\hline \multirow{22}{*}{ Vented } & Gas Well Completions without Hydraulic Fracturing & 0.00 & 0.00 & 0.00 & 0.00 & \multirow{7}{*}{ Drilling, compl. \& work. } & \multirow{7}{*}{5.5} \\
\hline & Gas Well Work-overs without Hydraulic Fracturing & 0.50 & 0.01 & -0.01 & 0.01 & & \\
\hline & Hydraulic Fracturing Completions and Work-overs that Vent & 192 & 4.8 & 0.00 & 4.8 & & \\
\hline & Flared Hydraulic Fracturing Completions and Work-overs & 3.9 & 0.10 & 0.00 & 0.1 & & \\
\hline & Hydraulic Fracturing Completions and Work-overs with RECs & 10 & 0.26 & 0.00 & 0.26 & & \\
\hline & Hydraulic Fracturing Completions and Work-overs with RECs that flare & 11 & 0.27 & 0.00 & 0.27 & & \\
\hline & Well Drilling & 1 & 0.02 & -0.01 & 0.01 & & \\
\hline & $\begin{array}{c}\text { Pneumatic Device Vents } \\
\end{array}$ & 1,208 & 30 & -22 & 8.4 & Pneum. devices & 8.4 \\
\hline & Chemical Injection Pumps & 67 & 1.7 & -0.07 & 1.6 & Chem. inject. pumps & 1.6 \\
\hline & Kimray Pumps & 388 & 9.7 & -5.1 & 4.6 & Kimray pumps & 4.6 \\
\hline & Dehydrator Vents & 121 & 3.0 & -0.97 & 2.1 & Dehydrators & 2.1 \\
\hline & Condensate Tanks without Control Device & 188 & 4.7 & -1.3 & 3.4 & \multirow{2}{*}{ Conden. tanks } & \multirow{2}{*}{4.1} \\
\hline & Condensate Tanks with Control Device & 38 & 0.94 & -0.25 & 0.69 & & \\
\hline & Gas Engine Exhaust & 266 & 6.6 & -3.5 & 3.1 & Gas engine exhaust & 3.2 \\
\hline & Liquids Unloading (with plunger lifts) & 119 & 3.0 & 0.00 & 3.0 & \multirow{2}{*}{ Liquids unloading } & \multirow[b]{2}{*}{6.8} \\
\hline & Liquids Unloading (without plunger lifts) & 155 & 3.9 & 0.00 & 3.9 & & \\
\hline & Vessel Blowdown & 0.70 & 0.02 & -0.01 & 0.01 & \multirow{6}{*}{ Blowdowns \& upsets } & \multirow{6}{*}{0.24} \\
\hline & Pipeline Blowdown & 2.8 & 0.07 & -0.04 & 0.03 & & \\
\hline & Compressor Blowdown & 2.7 & 0.07 & -0.04 & 0.03 & & \\
\hline & Compressor Starts & 6.1 & 0.15 & -0.01 & 0.14 & & \\
\hline & Pressure Relief Valves & 0.7 & 0.02 & -0.01 & 0.01 & & \\
\hline & Mishaps & 1.5 & 0.04 & -0.02 & 0.02 & & \\
\hline \multirow{2}{*}{$\begin{array}{c}\text { Fugitives and } \\
\text { Vented }\end{array}$} & Shallow Water Gas Platforms (Gulf of Mexico \& Pacific) & 266 & 6.6 & -3.5 & 3.1 & \multirow{2}{*}{ Offshore wells } & \multirow{2}{*}{3.4} \\
\hline & Deepwater Gas Platforms (Gulf of Mexico \& Pacific) & 23 & 0.58 & -0.31 & 0.27 & & \\
\hline
\end{tabular}

Acronyms: $\mathrm{CBM}=$ coal bed methane; $\mathrm{CH}_{4}=$ methane; chem. inject. = chemical injection; compl. = well completions; cond. = condensate; $\mathrm{Gg}=$ gigagrams; $\mathrm{MMt} \mathrm{CO}_{2} \mathrm{e}=$ million metric tonnes carbon dioxide equivalent; pneum. = pneumatic; $\mathrm{REC}=$ reduced emission completions; recip. compres. $=$ reciprocating compressor; sep. $=$ field separation equipment; work. $=$ well workovers.

Source: EPA 2014a

${ }^{33}$ The emission reductions reported in the table include an allocation of the "Other Production" emission reduction made in proportion to the contribution of an emission source category to total potential emissions for Production, Gathering and Boosting. 


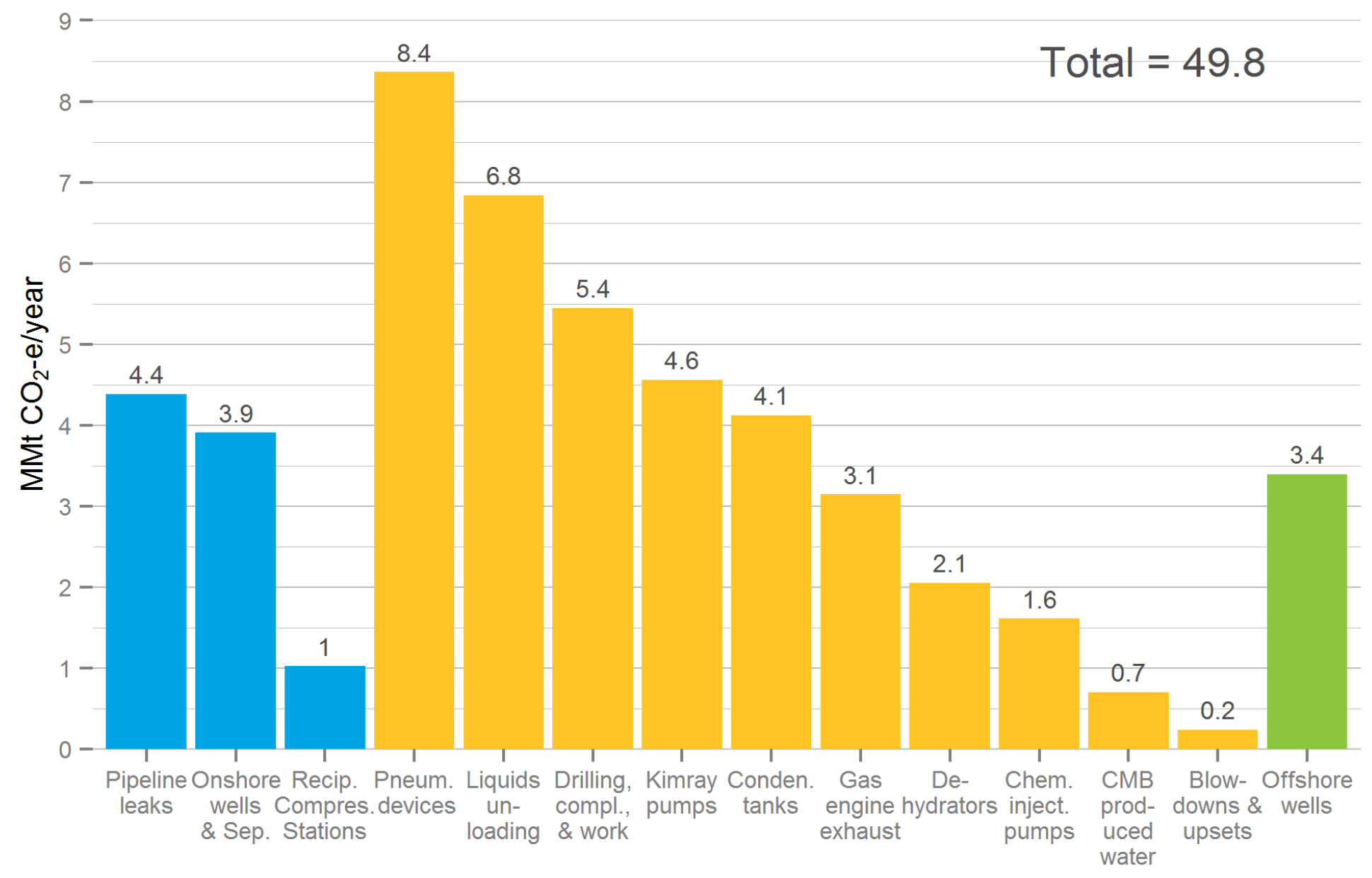

Fugitives Vented Fugitives or vented

Figure A-1. U.S. GHGI estimates of natural gas methane emissions in 2012 from the production and gathering and boosting segment of the natural gas supply chain. Acronyms: $\mathrm{CBM}=$ coal bed methane; $\mathrm{CH}_{4}=$ methane; chem inject. $=$ chemical injection; compl. = well

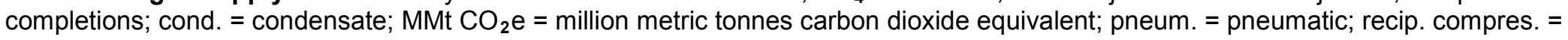
reciprocating compressor; sep. $=$ field separation equipment; work. $=$ well workovers

Source: EPA 2014a

\footnotetext{
${ }^{34}$ Figure A-1 is created from aggregated U.S. GHGI data shown in Table A-1 in Appendix A.
} 
Table A-2. U.S. GHGI Estimates of Natural Gas Methane $\left(\mathrm{CH}_{4}\right)$ Emissions in 2012 from the Processing Segment of the Natural Gas

Supply Chain. Light orange cells indicate where we have summed emissions reductions from voluntary and required emission reductions reported in U.S. GHGI. Dark orange cells shows the emission reduction we calculated from the "Other Processing" emission reduction category reported in the U.S. GHGI. ${ }^{35}$

\begin{tabular}{|c|c|c|c|c|c|c|c|}
\hline \multirow[t]{2}{*}{$\begin{array}{l}\text { Emission } \\
\text { Type }\end{array}$} & \multirow[t]{2}{*}{ Emission Source Category } & \multicolumn{2}{|c|}{$\begin{array}{l}\text { Potential } \\
\text { Emissions }\end{array}$} & \multirow{2}{*}{$\begin{array}{c}\begin{array}{c}\text { Emissions } \\
\text { Reductions }\end{array} \\
\text { MMt CO}{ }_{2} \mathrm{e} / \mathrm{yr}\end{array}$} & \multirow{2}{*}{$\frac{\text { Net Emissions }}{\text { MMit CO}}$} & \multirow[t]{2}{*}{$\begin{array}{c}\text { Figure A-2 Emission } \\
\text { Categories }\end{array}$} & \multirow{2}{*}{$\begin{array}{c}\text { Aggregated } \mathrm{Ne} \\
\text { Emissions }\end{array}$} \\
\hline & & $\mathrm{Gg} \mathrm{CH}_{4} / \mathrm{yr}$ & $\mathrm{MM} / \mathrm{C} \mathrm{CO}_{2} \mathrm{e} / \mathrm{yr}$ & & & & \\
\hline \multirow{4}{*}{ Fugitives } & Processing Plants & 34 & 0.84 & -0.28 & 0.56 & Processing plants & 0.56 \\
\hline & Reciprocating Compressors & 442 & 11 & 0.00 & 11 & Reciprocating compressors & 11 \\
\hline & Centrifugal Compressors (wet seals) & 238 & 5.9 & -2.0 & 4.0 & \multirow{2}{*}{ Centrifugal compressors } & \multirow{2}{*}{4.7} \\
\hline & Centrifugal Compressors (dry seals) & 44 & 1.1 & -0.37 & 0.73 & & \\
\hline \multirow{7}{*}{ Vented } & Gas Engine Exhaust & 187 & 4.7 & -0.15 & 4.5 & \multirow{2}{*}{ Gas E\&T exhaust } & \multirow{2}{*}{4.6} \\
\hline & Gas Turbine Exhaust & 5.3 & 0.13 & -0.04 & 0.09 & & \\
\hline & AGR Vents & 13 & 0.33 & 0.00 & 0.33 & AGR units & 0.33 \\
\hline & Kimray Pumps & 5.0 & 0.13 & -0.04 & 0.08 & Kimray pumps & 0.08 \\
\hline & Dehydrator Vents & 31 & 0.77 & -0.64 & 0.13 & Dehydrators & 0.13 \\
\hline & Pneumatic Devices & 1.9 & 0.05 & -0.02 & 0.03 & Pneumatic devices & 0.03 \\
\hline & Blowdowns & 47 & 1.2 & -0.40 & 0.79 & Blowdowns & 0.79 \\
\hline
\end{tabular}

Acronyms: $\mathrm{AGR}=$ acid gas removal; $\mathrm{CH}_{4}=$ methane; $\mathrm{E} \& \mathrm{~T}=$ engine and turbine; $\mathrm{Gg}=$ gigagrams; $\mathrm{MMt} \mathrm{CO}_{2} \mathrm{e}=\mathrm{million}$ metric tonnes carbon dioxide equivalent

\section{Source: EPA 2014a}

\footnotetext{
${ }^{35}$ The emission reductions reported in the table include an allocation of the "Other Processing" emission reductions made in proportion to the contribution of an emission source category to total potential emissions from the Processing segment.
} 


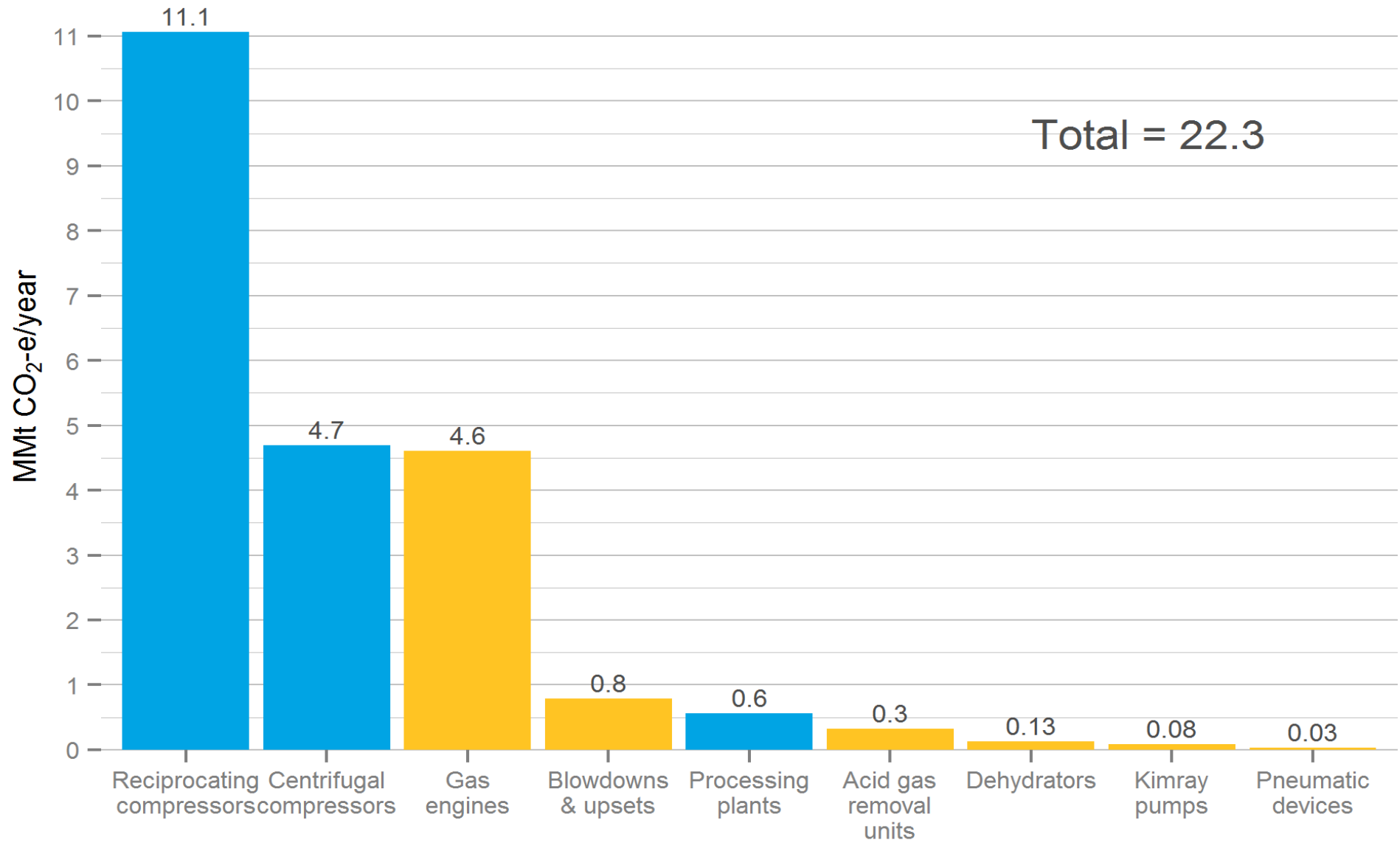

Fugitives

Vented

Figure A-2. U.S. GHGI estimates of natural gas methane emissions in 2012 from the processing segment of the natural gas supply chain. Acronyms: $\mathrm{AGR}=$ acid gas removal; $\mathrm{CH}_{4}=$ methane; $\mathrm{ET}=$ engine and turbine; $\mathrm{MMt} \mathrm{CO}_{2} \mathrm{e}=$ million metric tonnes carbon dioxide equivalent.

Source: EPA 2014a ${ }^{36}$

${ }^{36}$ Figure A-2 is created from aggregated U.S. GHGI data shown in Table A-2 in Appendix A. 
Table A-3. U.S. GHGI Estimates of Natural Gas Methane $\left(\mathrm{CH}_{4}\right)$ Emissions in 2012 from the Transmission and Storage Segment of the

Natural Gas Supply Chain. Light orange cells indicate where we have summed emissions reductions from voluntary and required emission

reductions reported in U.S. GHGI. Dark orange cells indicate emission reductions we calculated through an allocation procedure from a more general category. ${ }^{37}$ Red cells indicate where we used a different allocation procedure to calculate the reported emission reductions ${ }^{38}$ Purple cells indicate that for the aggregation of net emissions, we allocated "compressor station" fugitives between reciprocating and centrifugal compressors in proportion to total net emissions.

\begin{tabular}{|c|c|c|c|c|c|c|c|}
\hline \multirow[t]{2}{*}{$\begin{array}{c}\text { Emission } \\
\text { Type }\end{array}$} & \multirow[t]{2}{*}{ Emission Source Category } & \multicolumn{2}{|c|}{$\begin{array}{l}\text { Potential } \\
\text { Emissions }\end{array}$} & \multirow{2}{*}{$\begin{array}{c}\text { Emissions } \\
\text { Reductions } \\
\text { MMit } \mathrm{CO}_{2} \mathrm{e} / \mathrm{yr}\end{array}$} & \multirow{2}{*}{$\frac{\text { Net Emissions }}{\text { MMit } \mathrm{CO}_{2} \mathrm{e} / \mathrm{yr}}$} & \multirow[t]{2}{*}{$\begin{array}{c}\text { Figure A-3 Emission } \\
\text { Categories }\end{array}$} & \multirow{2}{*}{$\begin{array}{l}\text { Aggregated Net } \\
\text { Emissions } \\
\text { MiMt CO } \mathrm{CO}_{2} \mathrm{e} / \mathrm{yr}\end{array}$} \\
\hline & & $\mathrm{Gg} \mathrm{CH}_{4} / \mathrm{yr}$ & MMt $\mathrm{CO}_{2} \mathrm{e} / \mathrm{yr}$ & & & & \\
\hline \multirow{18}{*}{ Fugitives } & Compressor Stations $(\mathrm{T}]$ & 111.00 & 2.78 & -0.48 & 2.30 & & $-x^{2}$ \\
\hline & Compressor Stations (S) & 52.00 & 1.30 & -0.22 & 1.08 & - & - \\
\hline & Compressor Stations ( $\mathrm{T})$ - Reciprocating Compressor & 773.30 & 19.33 & -0.01 & 19.32 & Reciprocating & \\
\hline & Compressor Stations (S) - Reciprocating Compressor & 150.20 & 3.76 & 0.00 & 3.75 & compressor stations & 25.81 \\
\hline & Compressor Stations ( $\mathrm{T})$ - Centrifugal Compressor (wet seals) & 232.80 & 5.82 & -1.00 & 4.82 & \multirow{4}{*}{$\begin{array}{c}\text { Centrifugal } \\
\text { compressor stations }\end{array}$} & \multirow{4}{*}{6.35} \\
\hline & Compressor Stations (S) - Centrifugal Compressor (wet seals) & 22.30 & 0.56 & -0.10 & 0.46 & & \\
\hline & Compressor Stations ( $\mathrm{T})$ - Centrifugal Compressor (dry seals) & 15.00 & 0.38 & -0.06 & 0.31 & & \\
\hline & Compressor Stations (S) - Centrifugal Compressor (dry seals) & 6.50 & 0.16 & -0.03 & 0.13 & & \\
\hline & Storage Wells & 12.90 & 0.32 & -0.06 & 0.27 & \multirow{4}{*}{$\begin{array}{c}\text { Pipelines and storage } \\
\text { wells }\end{array}$} & \multirow{4}{*}{2.26} \\
\hline & Pipelines Leaks & 3.30 & 0.08 & -0.01 & 0.07 & & \\
\hline & Meters \& Regulators - Transmission Interconnect & 75.60 & 1.89 & -0.33 & 1.56 & & \\
\hline & Meters \& Regulators - Farm Taps \& Direct Sales & 17.50 & 0.44 & -0.08 & 0.36 & & \\
\hline & LNG Storage Stations & 10.60 & 0.27 & -0.05 & 0.22 & \multirow{6}{*}{$\begin{array}{l}\text { LNG compressor } \\
\text { stations }\end{array}$} & \multirow{6}{*}{1.50} \\
\hline & LNG Storage Reciprocating Compressors & 40.10 & 1.00 & -0.17 & 0.83 & & \\
\hline & LNG Storage Centrifugal Compressors & 13.80 & 0.35 & -0.06 & 0.29 & & \\
\hline & LNG Import Terminal Stations & 1.20 & 0.03 & -0.01 & 0.02 & & \\
\hline & LNG Import Terminal Reciprocating Compressors & 5.60 & 0.14 & -0.02 & 0.12 & & \\
\hline & LNG Import Terminal Centrifugal Compressors & 1.40 & 0.04 & -0.01 & 0.03 & & \\
\hline \multirow{15}{*}{ Vented } & Dehydrator Vents (S) & 4.00 & 0.10 & -0.02 & 0.08 & Dehydrators & 0.13 \\
\hline & Engine $(T)$ Exhaust & 235.30 & 5.88 & -2.85 & 3.03 & \multirow{6}{*}{ E-T-G exhaust } & \multirow{6}{*}{3.56} \\
\hline & Turbine $(\mathrm{T})$ Exhaust & 1.30 & 0.03 & -0.01 & 0.03 & & \\
\hline & Engine (S) Exhaust & 20.30 & 0.51 & -0.25 & 0.26 & & \\
\hline & Turbine (S) Exhaust & 0.20 & 0.01 & 0.00 & 0.00 & & \\
\hline & Generator (Engines) Exhaust & 11.50 & 0.29 & -0.05 & 0.24 & & \\
\hline & Generator (Turbines) Exhaust & 0.00 & 0.00 & 0.00 & 0.00 & & \\
\hline & Pneumatic Devices $(\mathrm{T})$ & 221.30 & 5.53 & -0.35 & 5.18 & \multirow{2}{*}{ Pneumatic devices } & \multirow{2}{*}{6.05} \\
\hline & Pneumatic Devices (S) & 42.30 & 1.06 & -0.18 & 0.87 & & \\
\hline & Pipeline Maintenance & 184.80 & 4.62 & -2.50 & 2.12 & Upsets & 2.12 \\
\hline & Compressor Station $(\mathrm{T})$ & 151.10 & 3.78 & -0.65 & 3.13 & \multirow{2}{*}{ Compressor stations } & \multirow{2}{*}{3.72} \\
\hline & Compressor Station (S) & 28.90 & 0.72 & -0.12 & 0.60 & & \\
\hline & LNG Storage Engines Exhaust & 2.70 & 0.07 & -0.01 & 0.06 & \multirow{3}{*}{ LNG E\&T exhaust } & \multirow{3}{*}{0.26} \\
\hline & LNG Storage Turbines Exhaust & 0.00 & 0.00 & 0.00 & 0.00 & & \\
\hline & LNG Storage Station & 5.90 & 0.15 & -0.03 & 0.12 & & \\
\hline
\end{tabular}

${ }^{37}$ The emission reductions reported in the table include an allocation of the "Other Transmission and Storage" emission reductions made in proportion to the contribution of an emission source category to total potential emissions for Transmission and Storage segment.

38 The emission reductions reported in the table include an allocation of emission reductions for "Reciprocating Engines" to transmission stations' and storage facilities' emission reductions in proportion to their contribution to total potential emissions for all reciprocating compressors in this segment. An analogous procedure was used for allocating emissions reductions for "Engine Exhaust". 


\begin{tabular}{|c|c|c|c|c|c|c|c|}
\hline \multirow[t]{2}{*}{$\begin{array}{l}\text { Emission } \\
\text { Type }\end{array}$} & \multirow[t]{2}{*}{ Emission Source Category } & \multicolumn{2}{|c|}{$\begin{array}{l}\text { Potential } \\
\text { Emissions }\end{array}$} & \multirow{2}{*}{$\begin{array}{l}\text { Emissions } \\
\text { Reductions } \\
\text { Milt } \mathrm{CO}_{2} \mathrm{e} / \mathrm{yr}\end{array}$} & \multirow{2}{*}{$\frac{\text { Net Emissions }}{\text { MMt } \mathrm{CO}_{2} \mathrm{e} / \mathrm{yr}}$} & \multirow[t]{2}{*}{$\begin{array}{c}\text { Figure A-3 Emission } \\
\text { Categories }\end{array}$} & \multirow{2}{*}{$\begin{array}{c}\begin{array}{c}\text { Aggregated Net } \\
\text { Emissions }\end{array} \\
\text { MMt CO } \mathrm{CO}_{2} \mathrm{e} / \mathrm{yr}\end{array}$} \\
\hline & & $\mathrm{Gg} \mathrm{CH}_{4} / \mathrm{yr}$ & $\mathrm{MMt} \mathrm{CO}_{2} \mathrm{e} / \mathrm{yr}$ & & & & \\
\hline & LNG Import Terminals Engines Exhaust & 3.60 & 0.09 & -0.02 & 0.07 & & \\
\hline & LNG Import Terminals Turbines Exhaust & 0.00 & 0.00 & 0.00 & 0.00 & & \\
\hline
\end{tabular}

Acronyms: $\mathrm{CH}_{4}$ = methane, E\&T = engine and turbine; E-T-G = engine, turbine and generator; Gg = gigagrams; $L N G$ = liquefied natural gas; $\mathrm{MMtCO}_{2} \mathrm{e}=$ million metric tonnes carbon dioxide equivalent; $\mathrm{T}=$ transmission; $\mathrm{S}=$ storage.

\section{Source: EPA 2014a}




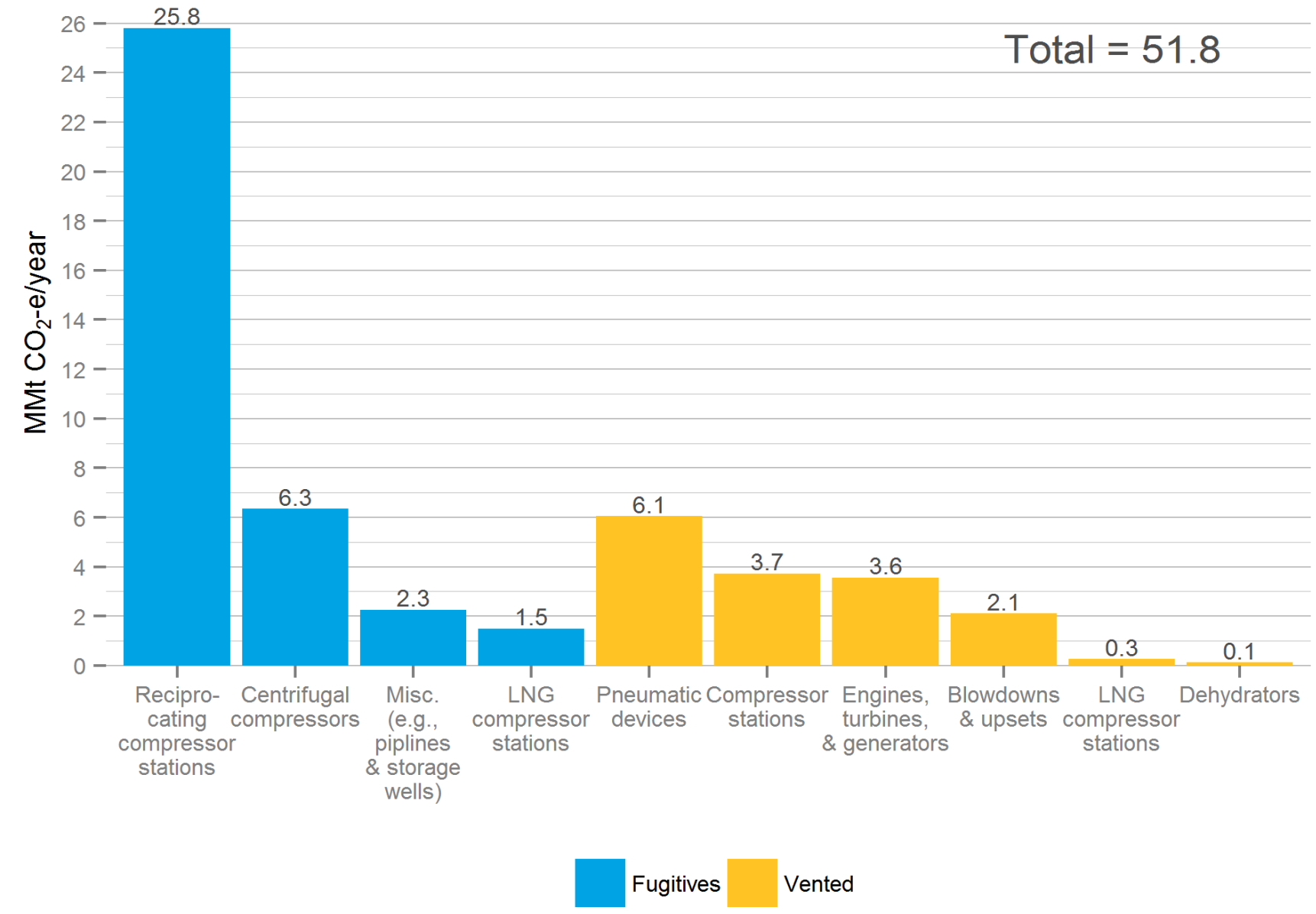

Figure A-3. U.S. GHGI estimates of natural gas methane emissions in 2012 from the transmission and storage segment of the natural gas supply chain. Acronyms: $\mathrm{CH}_{4}=$ methane, $\mathrm{ET}=$ engine and turbine; $\mathrm{ETG}=$ engine, turbine and generator; $\mathrm{LNG}=$ liquefied natural gas; $\mathrm{MMtCO}_{2} \mathrm{e}=$ million metric tonnes carbon dioxide equivalent.

Source: EPA $2014 a^{39}$

\footnotetext{
${ }^{39}$ Figure A-3 is created from aggregated U.S. GHGI data shown in Table A-3 in Appendix A.
} 
Table A-4. U.S. GHGI estimates of natural gas methane $\left(\mathrm{CH}_{4}\right)$ emissions in 2012 from the distribution segment of the natural gas supply chain. Light orange cells indicate the U.S. GHGI had an emission reduction due to existing control measures. Dark orange cells indicate that the U.S. GHGI had an "Other Distribution" emission reduction that we allocated to each emission source category in proportion to its potential emissions relative to total potential emissions.

\begin{tabular}{|c|c|c|c|c|c|c|c|}
\hline \multirow[t]{2}{*}{$\begin{array}{c}\text { Emission } \\
\text { Type }\end{array}$} & \multirow[t]{2}{*}{ Emission Source Category } & \multicolumn{2}{|c|}{$\begin{array}{l}\text { Potential } \\
\text { Emissions }\end{array}$} & \multirow{2}{*}{$\begin{array}{l}\text { Emissions } \\
\text { Reductions }\end{array}$} & \multirow{2}{*}{$\begin{array}{l}\text { Net Emissions } \\
\mathrm{MMt} \mathrm{CO} \mathrm{CO}_{2} \mathrm{yr}\end{array}$} & \multirow[t]{2}{*}{ Figure 4 Emission Categories } & \multirow{2}{*}{$\begin{array}{c}\begin{array}{c}\text { Aggregated Net } \\
\text { Emissions }\end{array} \\
\text { MMt } \mathrm{CO}_{2} \mathrm{e} / \mathrm{yr}\end{array}$} \\
\hline & & $\mathrm{Gg} \mathrm{CH}_{4} / \mathrm{yr}$ & MMt $\mathrm{CO}_{2} \mathrm{e} / \mathrm{yr}$ & & & & \\
\hline \multirow{20}{*}{ Fugitives } & Mains-Cast iron & 149 & 3.7 & 0.00 & 3.7 & Cast iron main lines & 3.7 \\
\hline & Mains_-Unprotected steel & 135 & 3.4 & -0.14 & 3.2 & \multirow{2}{*}{$\begin{array}{l}\text { Unprotected steel main \& service } \\
\text { lines }\end{array}$} & \multirow{2}{*}{6.3} \\
\hline & Services_Unprotected steel & 128 & 3.2 & -0.13 & 3.1 & & \\
\hline & Mains_-Protected steel & 29 & 0.72 & -0.03 & 0.69 & \multirow{2}{*}{ Protected steel main \& service lines } & \multirow{2}{*}{1.9} \\
\hline & Services Protected steel & 51 & 1.3 & -0.05 & 1.2 & & \\
\hline & Mains_-Plastic & 126 & 3.2 & -0.13 & 3.0 & \multirow{2}{*}{ Plastic pipe \& service lines } & \multirow{2}{*}{3.2} \\
\hline & Services-Plastic & 8.1 & 0.20 & -0.01 & 0.19 & & \\
\hline & Services-Copper & 4.9 & 0.12 & 0.00 & 0.12 & Copper service lines & 0.12 \\
\hline & Meters \& regulators $>300$ & 105 & 2.6 & -0.11 & 2.5 & \multirow{10}{*}{ Meters \& regulators (city gates) } & \multirow{10}{*}{12} \\
\hline & Meters \& regulators $100-300$ & 203 & 5.1 & -0.21 & 4.9 & & \\
\hline & Meters \& regulators $<100$ & 4.9 & 0.12 & 0.00 & 0.12 & & \\
\hline & Regulators $>300$ & 104 & 2.6 & -0.10 & 2.5 & & \\
\hline & Regulator-vault $>300$ & 0.50 & 0.01 & 0.00 & 0.01 & & \\
\hline & Regulators $100-300$ & 78 & 2.0 & -0.08 & 1.9 & & \\
\hline & Regulator-vault $100-300$ & 0.20 & 0.01 & 0.00 & 0.00 & & \\
\hline & Regulators $40-100$ & 6.0 & 0.15 & -0.01 & 0.14 & & \\
\hline & Regulators-vault 40-100 & 0.40 & 0.01 & 0.00 & 0.01 & & \\
\hline & Regulators $<40$ & 0.30 & 0.01 & 0.00 & 0.01 & & \\
\hline & Residential customer meters & 99 & 2.5 & -0.10 & 2.4 & \multirow{2}{*}{ Customer meters } & \multirow{2}{*}{2.5} \\
\hline & Commercial/industry customer meters & 4.1 & 0.10 & 0.00 & 0.10 & & \\
\hline \multirow{3}{*}{ Vented } & Pressure relief valve releases & 1.2 & 0.03 & 0.00 & 0.03 & \multirow{3}{*}{ Blowdowns \& upsets } & \multirow{3}{*}{0.95} \\
\hline & Pipeline blowdown & 2.3 & 0.06 & 0.00 & 0.06 & & \\
\hline & Upsets/mishaps (dig-ins) & 35 & 0.89 & -0.02 & 0.87 & & \\
\hline
\end{tabular}

Acronyms: $\mathrm{CH}_{4}=$ methane, $\mathrm{Gg}$ = gigagrams; $\mathrm{MMt} \mathrm{CO}_{2} \mathrm{e}=$ million metric tonnes carbon dioxide equivalent; $\mathrm{M} \& \mathrm{R}=$ meters and regulators.

Source: EPA 2014a 


\section{Appendix B. Inventory Studies}

Figure B-1 shows other regional and state emission inventories in the United States. Inventories including GHG emissions as well as other emissions are included. As illustrated below, most inventories focused on criteria air pollutants like nitrous oxides and particulate emissions. Most GHG inventories are also focused on a small geographic area.

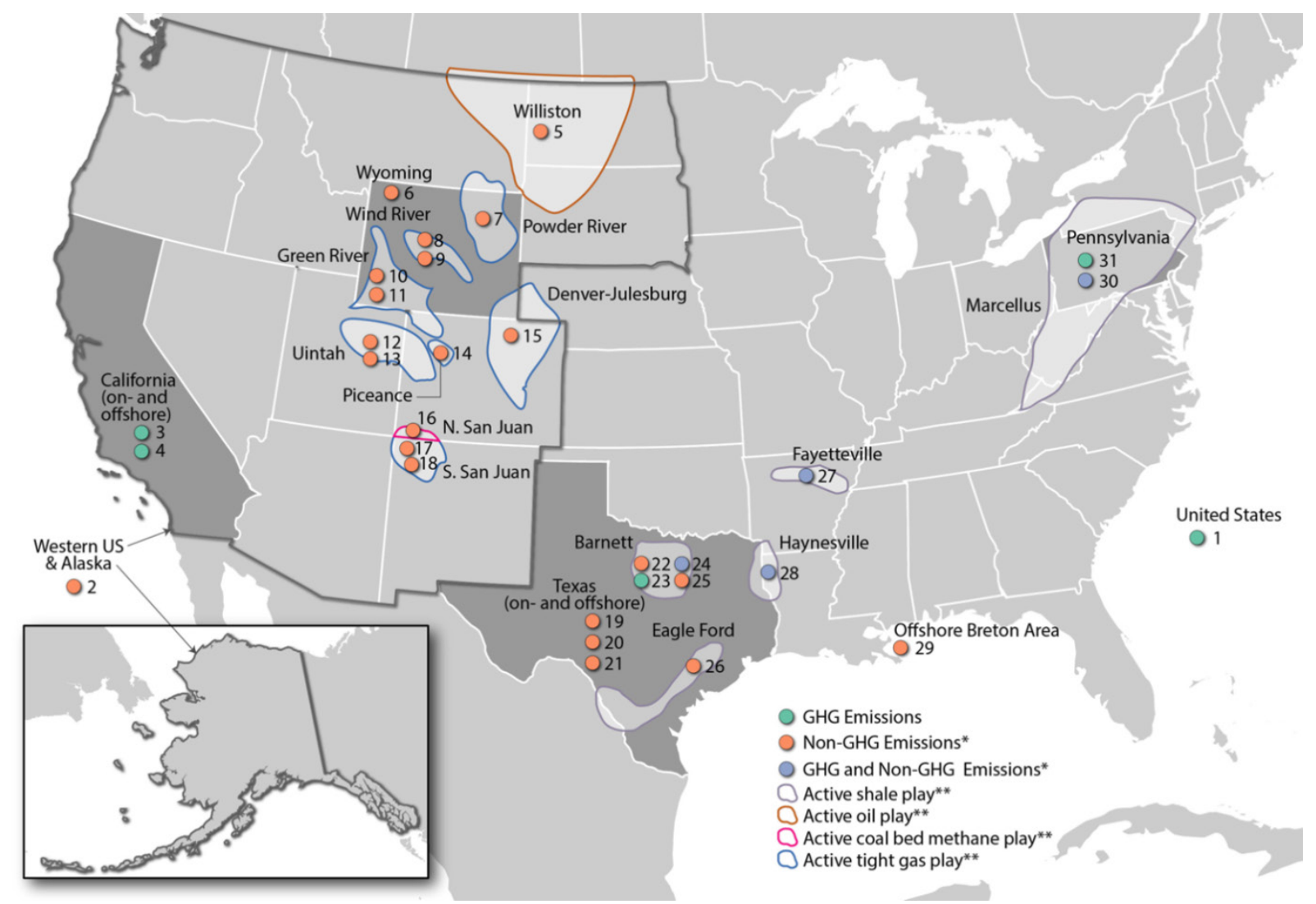

Figure B-1. Emission inventory studies through May 2014, aggregated by the type of emissions included and by location. See Section 7 for the numbered inventory study reference list. National studies are listed to the side of the map. Studies conducted within unspecified areas are shown labeled by states in darker grey. The portions of the natural gas supply chain covered by the studies are: production, gathering, and boosting: all studies; transmission, storage and processing: 1, 3, 4, 23, 24, 27 , 31; and distribution: 1, 3, 23, 31.

* Non-GHGs include VOCs, HAPs, PM, and others.

** Only active plays relevant to current and known forthcoming studies are shown (Oil and Gas Journal 2014). 